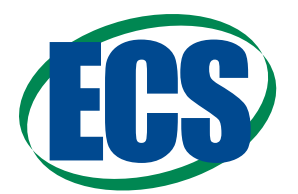

\title{
A Shrinking-Core Model for the Degradation of High-Nickel Cathodes (NMC811) in Li-Ion Batteries: Passivation Layer Growth and Oxygen Evolution
}

\author{
Abir Ghosh, ${ }^{1,2,4, z}$ (i) Jamie M. Foster, ${ }^{2,3}$ Gregory Offer, ${ }^{1,2, *}$ and Monica Marinescu ${ }^{1,2}$ (i) \\ ${ }^{1}$ Department of Mechanical Engineering, Imperial College London, SW7 2AZ, United Kingdom \\ ${ }^{2}$ The Faraday Institution, United Kingdom \\ ${ }^{3}$ School of Mathematics and Physics, University of Portsmouth, Hampshire PO1 2UP, United Kingdom \\ ${ }^{4}$ Department of Chemical Engineering \& Technology, Indian Institute of Technology (BHU), Varanasi 221005, India
}

\begin{abstract}
A degradation model for high-nickel positive electrode materials that undergo a structural reorganisation involving oxygen loss and the formation of a disordered (spinel or rock-salt structure) passivation layer is presented for the first time. The model is a thermally coupled continuum model based on the single-particle model and is based upon a $\mathrm{LiNi}_{0.8} \mathrm{Mn}_{0.1} \mathrm{Co}_{0.1} \mathrm{O}_{2}(\mathrm{NMC} 811)$ layered oxide in this instance. The theoretical framework assumes a shrinking core mechanism, where lattice oxygen, [O], release occurs at the interface between the bulk and the passivation layer, and the rate of reaction is controlled by either [O]-diffusion through the passivation layer or the reaction kinetics at the interface. As the passivation layer grows, the core of active positive electrode material shrinks giving rise to both loss in active material (LAM) and loss in lithium inventory (LLI) through trapping lithium in the passivation layer, giving rise to capacity fade. The slower diffusion of lithium through the passivation layer also gives rise to power fade. The model predicts two limiting cases, "diffusion dominated" if [O]-diffusion is slow, and "reaction dominated" if [O]-diffusion is fast, relative to the reaction rate of [O]-release and also the thickness of the passivation layer.

(C) 2021 The Author(s). Published on behalf of The Electrochemical Society by IOP Publishing Limited. This is an open access article distributed under the terms of the Creative Commons Attribution 4.0 License (CC BY, http://creativecommons.org/licenses/ by/4.0/), which permits unrestricted reuse of the work in any medium, provided the original work is properly cited. [DOI: 10.1149/ 1945-7111/abdc71]
\end{abstract}

Manuscript submitted October 14, 2020; revised manuscript received December 30, 2020. Published February 3, 2021. This paper is part of the JES Focus Issue on Selected Papers of Invited Speakers to IMLB 2020.

Supplementary material for this article is available online

Li-ion batteries are the energy storage of choice for the rapidly increasing market of electric and hybrid vehicles. ${ }^{1}$ Their uptake would be significantly increased if the cycle life of these batteries for relevant operational conditions were improved. The study of degradation mechanisms is important to make knowledge available for battery manufacturers to produce Li-ion batteries with higher specific capacity at a significantly lower cost. ${ }^{2,3}$ In this regard, the choice of the positive electrode (PE) active material ${ }^{4,5}$ of Li-ion batteries and their degradation mechanisms ${ }^{6}$ play a major role. High-nickel layered lithium nickel manganese cobalt oxide $\left(\mathrm{LiNi}_{\mathrm{x}} \mathrm{Mn}_{\mathrm{y}} \mathrm{Co}_{\mathrm{z}} \mathrm{O}_{2}, \mathrm{NMC}\right) \mathrm{PE}$ active materials are now preferred because of their high specific capacity and stable layered structures for the intercalation and deintercalation of Li-ions. ${ }^{7-10}$ Even though the theoretical capacity of NMCs is as high as $\sim 280 \mathrm{mAh} \mathrm{g}^{-1},{ }^{11} \mathrm{LiNi}_{0.8} \mathrm{Mn}_{0.1} \mathrm{Co}_{0.1} \mathrm{O}_{2}$ (NMC811) provides the highest reversible capacity in practice $\left(\sim 200 \mathrm{mAh} \mathrm{g}^{-1}\right)$ than other NMC compositions. ${ }^{4,12}$ The higher reversible capacity is attainable due to the presence of more extractable Li-ions within the usable voltage window. However, NMC811 structures are not stable when a large fraction of Li-ions are removed during charging of the cell and the structures are susceptible to capacity loss. ${ }^{13,14}$

High-nickel NMC structures are thermally less stable at high temperatures $\geqslant 170{ }^{\circ} \mathrm{C}$ rather than at room temperature. ${ }^{15-17}$ However, Li-ion-depleted layered oxide NMC811 structures are thermodynamically unstable even at battery operating temperature $\left(20{ }^{\circ} \mathrm{C}-80{ }^{\circ} \mathrm{C}\right)$ when cycled at higher potentials $\left(\sim 4.3 \mathrm{~V}\right.$ vs $\left.\mathrm{Li}^{\prime} / \mathrm{Li}^{+}\right)$. The layered structures undergo a two-phase transition to form disordered spinel $\left(\mathrm{Li}\left(\mathrm{Ni}_{0.8} \mathrm{Mn}_{0.1} \mathrm{Co}_{0.1}\right)_{3} \mathrm{O}_{4}\right)$ and rock-salt $\left(\mathrm{LiNi}_{0.8} \mathrm{Mn}_{0.1} \mathrm{Co}_{0.1} \mathrm{O}\right)$ structures, sequentially. ${ }^{18,19}$ Both phase transition steps are accompanied by the release of lattice oxygen, [O]. ${ }^{11,15-23}$ For NMC811 materials ageing below $60{ }^{\circ} \mathrm{C}$, the spinel and rock-salt surface layer formation happens at the electrode surface while the bulk remains intact which increases the overpotential at the electrode. ${ }^{11,22}$ Several experimental studies have claimed that the increase in the overpotential causes a significant capacity fade. ${ }^{22}$ The formation of $[\mathrm{O}]$ from the phase

*Electrochemical Society Member.

${ }^{\text {z } E-m a i l: ~ a b i r . g h o s h @ i m p e r i a l . a c . u k ; ~ a b i r . c h e @ i i t b h u . a c . i n ~}$ transition reaction is also one of the sources of $\mathrm{O}_{2}, \mathrm{CO}_{2}$, and $\mathrm{CO}$ although these can also be formed from the electrochemical oxidation of the electrolytes. ${ }^{22,24} \mathrm{~A}$ recent study has shown an increase in temperature increases the amount of $\mathrm{O}_{2}$ evolution by forming thicker surface layers. ${ }^{25}$ The instantaneous formation of disordered spinel and rock-salt surface layer has been observed experimentally once the electrode is exposed to the electrolyte solution even without any electrochemical cycling. ${ }^{26}$ The formation of the surface layer is not only limited to high-nickel NMCs or other NMC compositions, ${ }^{11}$ but has also been reported for $\mathrm{LiNiO}_{2},{ }^{27} \mathrm{LiNi}_{0.8} \mathrm{Co}_{0.2} \mathrm{O}_{2},{ }^{28,29}$ and $\mathrm{LiNi}_{\mathrm{x}} \mathrm{Co}_{\mathrm{y}} \mathrm{Al}_{\mathrm{z}} \mathrm{O}_{2}(\mathrm{NCA})^{30}$ active materials. A wide range of surface layer thickness from $15 \mathrm{~nm}-100 \mathrm{~nm}$ has been reported for different battery chemistries at different cycling, operating, and storage conditions. $^{11,27,28}$

To date, theoretical degradation studies of PEs have been limited to empirical fitting. ${ }^{31,32}$ A few molecular-scale studies have confirmed the transition of layered NMC structures to disordered spinel and rocksalt surface layers and the thermodynamic stability of the surface layers over the Li-ion-depleted layered structures. ${ }^{33}$ The influence of this structural phase change, $\mathrm{O}_{2}$ evolution, and other PE degradation mechanisms such as transition metal (TM) dissolution ${ }^{34-36}$ and positive electrode solid electrolyte layer (pSEI) formation, ${ }^{37,38}$ on the cell storage and operating performance (such as capacity fade and impedance rise) have not been studied theoretically. On the contrary, many detailed negative electrode (NE) degradation studies where the physics of specific degradation mechanisms such as solid electrolyte layer (SEI) growth, ${ }^{39-42}$ Li-plating, ${ }^{43,44}$ loss of active material, ${ }^{45,46}$ and particle cracking ${ }^{47}$ have been explored, as well as their influence on the cell behaviour. Only a few studies including PE degradation are mostly integrated within whole-cell coupled degradation modelling studies without exploring the appropriate physics of specific PE degradation mechanisms. ${ }^{48,49}$ The release of $\mathrm{O}_{2}$ from $\mathrm{PE}$ has been conventionally modelled as electrolyte oxidation at the PE side, using a simple kinetically limited Tafel equation. ${ }^{49}$ A recent study proposed that the capacity fade is a linear function of the oxidation current density and used the Tafel equation to model the oxidation rate. ${ }^{50}$ The electrolyte oxidation reaction also produces protons $\left(\mathrm{H}^{+}\right)$which are eventually consumed at the NE surface to produce $\mathrm{H}_{2}$, which in turn 
promotes TM dissolution. ${ }^{48,49}$ There are few shrinking core models exists to track the phase transition of electrodes for different $P E$ active materials. ${ }^{51,52}$ However, the lack of a consensus on the equations to describe PE degradation motivates the present study.

In summary, the phase transition of high-nickel NMCs due to structural reconstruction during high potential cycling or storage is frequently encountered in experiments $22,24-26,35$ and thus an important PE degradation mechanism. However, there are no studies that have attempted modelling of this phenomenon by understanding the physics behind this degradation mechanism. Thus, no whole-cell coupled degradation model is complete where PE undergoes structural reconstruction. In this study, a continuum scale model is developed based upon a theoretical framework considering structural changes in a high-nickel NMC and how this affects the degradation of a Li-ion cell, for the first time. The developed model can be used as a missing-link to incorporate this degradation mechanism in the whole-cell continuum scale degradation models based on either single-particle models (SPMs), ${ }^{49,53-55}$ as presented in this study, or pseudo-2D models ${ }^{48,56}$ of Li-ion batteries. The cell considered in this study is a commercial 3.35 Ah Li-ion battery (INR18650-MJ1, LG Chem ${ }^{57}$ ) with NMC811/ $\mathrm{SiC}$ chemistry, where the acronym "SiC" stands for silicon doped graphite NEs. ${ }^{58}$ A thermally coupled $\mathrm{SPM}^{55}$ is modified to incorporate the dynamics of surface layers and the diffusion of the evolved-[O]. The disordered surface layers act as a passivation layer (PL), which resists the diffusion of Li-ions during intercalation/deintercalation which increases the resistance of the cell. The mechanisms modelled are based on hypotheses corresponding to experimental observations. The model developed here does not contain degradation in the NE, as the study is focused on the influence of structural changes of PE active materials on cell behaviour. The results obtained using the developed model are compared and contrasted with those available for the conventional beginning of life (BOL) SPM.

\section{Theoretical Formulation}

Figure 1 schematically shows the modified single-particle method (mSPM) used to study the degradation of an NMC811 positive electrode (PE) because of the passivation layer (PL) formation and [O]-evolution. The model presented in this current work is developed based on the previous single-particle models
(SPMs). ${ }^{53-55}$ A SPM is common in Li-ion battery modelling and the model assumes that even though each electrode is comprised of many different electrode particles, the behaviour of each of these particles is sufficiently similar that no significant errors are engendered by solving in just one representative particle. ${ }^{59,60}$ The SPM is chosen for this study because it is the simplest model within which to demonstrate a new degradation model and is suitable to treat the operational conditions considered in this study. According to the experimental observations mention in the previous section the PL forms at the surface of PE particles while the bulk of the electrode remains non-degraded. Thus, the PE particle in the mSPM consists of the non-degraded layered NMC (termed as "core") and the degraded disordered NMC (termed as "shell"), as shown in Fig. 1b. Subsequently, the shell thickens to increase the degradation in the $\mathrm{PE}$ which is accounted for in the mSPM by capturing the movement of the core-shell interface. The shell can be an individual spinel, or rock-salt phase, or a combination of both phases. ${ }^{22}$ They are lumped together in this model, but the effect of different shell layers can be accounted for by varying the average properties of the shell without changing the theoretical formulation presented.

In the formulation, the notation, $t$, represents time and bold variables denote vectors. The variables with subscripts preceded by a comma represent partial differentiation with respect to the subscripted variable and the over-dot represents the total time derivative.

Positive electrode (PE).-Hypothesis.-Based on the available experimental studies on the structural changes of NMC-based PEs, the following assumptions were made,

(i) The validity of our model begins after the first cycle during which it is assumed that a thin shell has already formed on the particle surface. ${ }^{22,26}$ Therefore, in the mSPM, we have assumed a combined core-shell structure as the initial configuration. The core and shell region of the PE particle can be defined as, $r \in(0, s(t))$ and $r \in\left(s(t), R_{\mathrm{p}}\right)$, respectively. Here, $s$ represents the position of the core-shell interface and $R_{\mathrm{p}}$ is the radius of the particle boundary.

(ii) The transition of the NMC811 layered structure to shell structure is thermodynamically more favourable at low stoichiometries

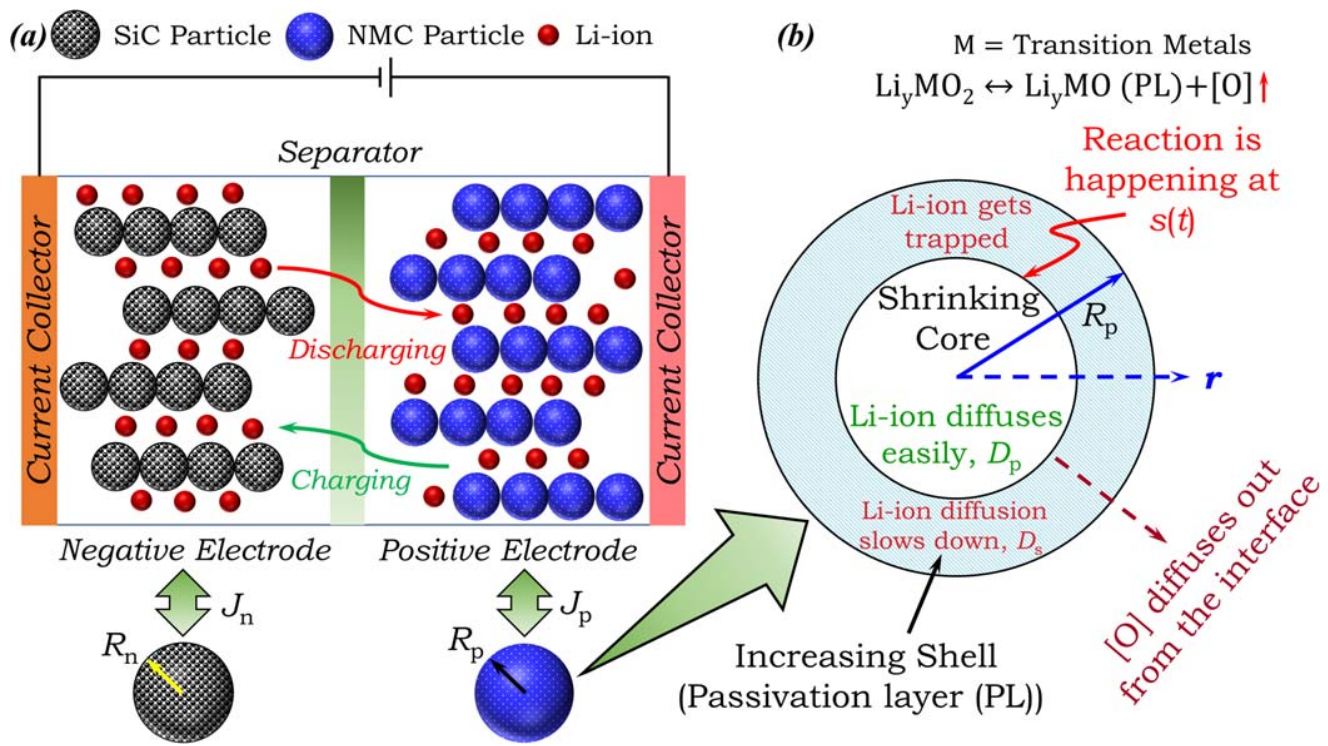

Figure 1. (a) Schematic representation of a rechargeable Li-ion battery, consisting of negative electrode (NE), positive (PE) electrode, separator, and current collectors and simplification of the same to the single-particle model (SPM). Silicon doped graphite (SiC) and high-nickel nickel manganese cobalt oxide (NMC811) are chosen as NE and PE materials, respectively. $R_{\mathrm{n}}$ and $R_{\mathrm{p}}$ are the radii of the equivalent single intercalation particle of the entire NE and PE, respectively. $J_{\mathrm{n}}$ and $J_{\mathrm{p}}$ are the molar fluxes of Li-ions at the surface of the NE and PE, respectively. (b) Modified PE particle morphology of the proposed mSPM, consisting of a shrinking core (non-degraded layered transition metal oxides, $\mathrm{Li}_{\mathrm{y}} \mathrm{MO}_{2}$ ) and an increasing shell (degraded disordered rock-salt phase, $\mathrm{Li}_{\mathrm{y}} \mathrm{MO}$ ) inside the particle surface. Li-ions diffuse slower in the shell, which is created by the phase transition reaction leading to diffusion of [O] from the dynamic core-shell interface, $s(t)$ 
(i.e. corresponding to high cell state of charge $(\mathrm{SoC})) .{ }^{11}$ To capture this effect in the mSPM, we consider that the chemical reaction that forms the shell occurs at the core-shell interface, $s(t)$, and only when the local concentration of Li-ions $\left(c_{\mathrm{p}}\right)$ at the core-shell interface, $s(t)$, is less than a critical concentration of Li-ions in the PE $\left(c^{*}\right)$ i.e., $\left.c_{\mathrm{p}}\right|_{r=s}<c^{*}$. The shell thickness increases when this formation reaction takes place. Simultaneously, the core of the PE shrinks (shrinking core) by the same thickness, to maintain the size of the particle. This can be replaced with a more complex relationship if required in a later evolution of the model.

(iii) The diffusion of Li-ions across the particle is slower through the disordered shell. ${ }^{61}$ Therefor, in the mSPM, the effective diffusivity of Li-ions in the shell $\left(D_{\mathrm{s}}\right)$ is assumed to be lower than the effective diffusivity of the Li-ions in the core $\left(D_{\mathrm{p}}\right)$.

(iv) The formation of the shell leads to loss of lithium inventory (LLI). During the formation of the shell, the chemical reaction $\left(\mathrm{Li}_{y} M O_{2} \leftrightarrow \mathrm{Li}_{y} \mathrm{MO}+[O]\right)$ consumes $\mathrm{Li}$-ions, ${ }^{2,24,36}$ and the resulting shell is assumed to be comprised of a fraction $(1-\phi)$ of degraded disordered NMC material and a fraction $\phi$ of active layered NMC811. The non-degraded material that remains in the shell provides the intercalation sites on which the redox reactions take place, and these rates are assumed to be well-described by Butler-Volmer kinetics. It follows that the overall capacity of the shell is $c_{\mathrm{s}}^{\max }=\phi c_{\mathrm{p}}^{\max }$ and that the LLI is $c_{\mathrm{s}}^{\max } / c_{\mathrm{p}}^{\max }=\phi$. Since $\phi<1$ is Li-ions are consumed in the reaction that forms the shell.

(v) The $[\mathrm{O}]$ produced from the chemical reaction diffuses out from the PE to create $\mathrm{O}_{2}, \mathrm{CO}_{2}$, and $\mathrm{CO}$ evolution. ${ }^{22,24}$ Therefore, in the mSPM, the [O] is diffusing out from the core-shell interface, $s(t)$, with an effective diffusivity, $D_{\mathrm{o}}$. We do not account for the further effects of gas generation, such as pressure change within the cell and loss of interfacial area.

Governing equations. - The diffusion of Li-ions through the core and shell is governed by the Fick's second law,

$$
\begin{gathered}
c_{\mathrm{p}, t}+\nabla \cdot \mathbf{F}_{\mathrm{p}}=0 \text { in } 0<r<s(t), \\
\left(\phi c_{\mathrm{s}}\right)_{t}+\nabla \cdot \mathbf{F}_{\mathrm{s}}=0 \text { in } s(t)<r<R_{\mathrm{p}} .
\end{gathered}
$$

Here, $\mathbf{F}_{\mathrm{p}}\left(=-D_{\mathrm{p}} \nabla c_{\mathrm{p}}\right)$ is the local mass flux of Li-ions in the core and $\mathbf{F}_{\mathrm{s}}\left(=-D_{\mathrm{s}} \nabla c_{\mathrm{s}}\right)$ is the effective mass flux of Li-ions in the shell. We emphasize that we use the term effective in the latter case because the shell is composed of multiple materials and $\mathbf{F}_{\mathrm{s}}$ is the number of mols of Li-ions passing a unit area of the composite per unit time and not the local flux within the non-degraded portion of the shell. The variables, $c_{\mathrm{p}}$ and $c_{\mathrm{s}}$ are the local concentration of Li-ions in the core and shell, respectively.

The diffusion of the [O] through the shell is also governed by the Fick's second law as,

$$
c_{\mathrm{o}, t}+\nabla \cdot \mathbf{F}_{\mathrm{o}}=0 \text { in } s(t)<r<R_{\mathrm{p}},
$$

where $\mathbf{F}_{\mathrm{o}}\left(=-D_{\mathrm{o}} \nabla c_{\mathrm{o}}\right)$ and $c_{\mathrm{o}}$ are the local mass flux and concentration of oxygen in the shell, respectively.

Boundary conditions. - The following boundary conditions are used. The particle flux of Li-ions at the centre $(r=0)$ of the electrode particle is zero due to symmetry. However, the Li-ions particle flux at the electrode particle boundary $\left(r=R_{\mathrm{p}}\right)$ is equal to the molar flux, $J_{\mathrm{p}}$, which is related to the total applied current, $I_{\text {app }}$, passing through the cell and the total electroactive surface area of the PE, $A_{\mathrm{p}}$. Thus, the boundary conditions are

$$
\left.F_{\mathrm{p}}\right|_{r=0}=0,
$$

$$
\left.F_{\mathrm{s}}\right|_{r=R_{\mathrm{p}}}=J_{\mathrm{p}}=I_{\mathrm{app}} / F A_{\mathrm{p}} .
$$

Here, $F$ is the Faraday's constant while $F_{\mathrm{s}}$ and $F_{\mathrm{p}}$ are the $r$ directional mass fluxes of Li-ions in the shell and core, respectively. In this work, we have defined $I_{\text {app }}$ as positive during charging of the cell and negative during discharging of the cell. The total electroactive area can be given by, $A_{\mathrm{p}}=3 \varepsilon_{\mathrm{p}} V_{\mathrm{p}} / R_{\mathrm{p}}$, where, $\varepsilon_{\mathrm{p}}$ is the volume fraction of the active material of the electrode and $V_{\mathrm{p}}$ is the total volume of the electrode.

One of the boundary conditions at the core-shell interface $(r=s)$ is that the concentrations of $\mathrm{Li}$-ions at the interface must be continuous

$$
\left.c_{\mathrm{p}}\right|_{r=s}=\left.c_{\mathrm{s}}\right|_{r=s} .
$$

The second boundary condition at the core-shell can be determined from the facts that $(i) \mathrm{Li}$-ions available for intercalation/deintercalation can either leave through the particle surface or be consumed in the shell, and (ii) the total number of Li-ions is conserved. Using these constraints together with Eq. 6, the second boundary condition at $r=s$ becomes

$$
\left.\left(F_{\mathrm{s}}-F_{\mathrm{p}}\right)\right|_{r=s}+\left.\dot{s}(1-\phi) c_{\mathrm{p}}\right|_{r=s}-\dot{s} c_{\mathrm{oc}}=0,
$$

where $c_{\mathrm{oc}}$ is the [O]-concentration in the core which is a constant. A step by step derivation of Eq. 7 is provided in Appendix A. The initial concentrations of Li-ions in the core and shell are

$$
\left.c_{\mathrm{p}}\right|_{t=0}=\left.c_{\mathrm{s}}\right|_{t=0}=c_{\mathrm{pi}} \text {. }
$$

The boundary condition for [O]-diffusion at the core-shell interface $(r=s)$ can be derived from the fact that the total amount of oxygen contained within PE particle and leaving the particle surface is conserved. The [O]-concentration is assumed to be zero at the particle-electrolyte boundary $\left(r=R_{\mathrm{p}}\right)$ because the [O] at the particle boundary is expected to react very fast. Thus, the boundary conditions for [O]-diffusion are

$$
\begin{gathered}
\left.F_{\mathrm{o}}\right|_{r=s}+\left.\dot{s}\left(c_{\mathrm{oc}}-c_{\mathrm{o}}\right)\right|_{r=s}=0, \\
\left.c_{\mathrm{o}}\right|_{r=R_{\mathrm{p}}}=0 .
\end{gathered}
$$

Here, $F_{\mathrm{o}}$ denotes the $r$-directional mass flux of [O] in the shell. A step by step derivation of Eq. 9 is provided in Appendix A. The initial $[\mathrm{O}]$-concentration in the shell is assumed to be

$$
\left.c_{\mathrm{o}}\right|_{t=0}=0 \text {, }
$$

and increased while the shell thickens. This also indicates that we always start our simulations a long period after the thin shell has formed on the particle surface.

Core-shell interface.-The core-shell interface may advance towards the centre of the particle whenever the Li-ion concentration $\left(c_{\mathrm{p}}\right)$ at the interface is below the critical concentration $\left(c^{*}\right)$ that allows the NMC phase transition reaction to occur

$$
\mathrm{Li}_{\mathrm{y}} \mathrm{MO}_{2} \underset{k_{2}^{\prime}}{\stackrel{k_{1}^{\prime}}{\rightleftharpoons}} \mathrm{Li}_{\mathrm{y}} \mathrm{MO}+[\mathrm{O}],
$$

where $k_{1}^{\prime}$ and $k_{2}^{\prime}$ denote the forward and backward chemical reaction rate constants, respectively. The reaction kinetics of Eq. 12 governs the interface dynamics in terms of redefined reaction rate constants $\left(k_{1}\right.$ and $\left.k_{2}\right)$ and concentration of [O] $\left(c_{\mathrm{o}}\right)$ as,

$$
\dot{s}=-\left\{\begin{array}{cc}
k_{1}-k_{2} c_{\mathrm{o}} & c_{\mathrm{p}}<c * \\
0 & c_{\mathrm{p}}>c *
\end{array}\right\} .
$$


Here, the backward reaction is rate-limiting as this requires oxygen which may not be available. The redefined reaction rate constants are explained in the derivation of Eq. 13 provided in Appendix A.

Negative electrode (NE).- - The governing equations and boundary conditions used for the $\mathrm{NE}$ in the proposed $\mathrm{mSPM}$ are similar to those used in conventional SPM models. ${ }^{55}$ The diffusion of Li-ions through the NE is governed by Fick's second law and mass flux boundary conditions at the centre of the particle and the particle-electrolyte interface are supplied. Thus, Li-ion diffusion equations at the $\mathrm{NE}$ are,

$$
\begin{gathered}
c_{\mathrm{n}, t}+\nabla \cdot \mathbf{F}_{\mathrm{n}}=0, \\
\left.F_{\mathrm{n}}\right|_{r=0}=0, \\
\left.F_{\mathrm{n}}\right|_{r=R_{\mathrm{n}}}=J_{\mathrm{n}}=-I_{\text {app }} / F A_{\mathrm{n}} .
\end{gathered}
$$

Here, $c_{\mathrm{n}}$ and $\mathbf{F}_{\mathrm{n}}\left(=-D_{\mathrm{n}} \nabla c_{\mathrm{n}}\right)$ denote local Li-ion concentration and local mass flux of Li-ions in the $\mathrm{NE}$, with $D_{\mathrm{n}}$, the effective diffusivity of $\mathrm{Li}$-ions in the NE. $F_{\mathrm{n}}$ represents the $r$-directional particle flux of Li-ions and $J_{\mathrm{n}}$ is the molar flux of Li-ions at the electrode surface. The total electroactive area of the electrode $\left(A_{\mathrm{n}}\right)$ can be defined as, $A_{\mathrm{n}}=3 \varepsilon_{\mathrm{n}} V_{\mathrm{n}} / R_{\mathrm{n}}$, where, $\varepsilon_{\mathrm{n}}$ and $V_{\mathrm{n}}$ represent the volume fraction of solid-phase active material and the total volume of the electrode, respectively. The initial concentration of Li-ions in the NE is,

$$
\left.c_{\mathrm{n}}\right|_{t=0}=c_{\mathrm{ni}}
$$

Electrochemical reaction kinetics.-Electrochemical reactions happen at the electrode-electrolyte interface of each electrode as a result of $\mathrm{Li}$-ions intercalation/deintercalation. The rate of such reactions is assumed to follow Butler-Volmer (BV) kinetics,

$$
\begin{gathered}
J_{\mathrm{i}}=k_{0 \mathrm{i}} c_{\mathrm{e}}^{\alpha}\left(c_{\mathrm{i}}^{\text {max }}-c_{\mathrm{i}}^{\text {surf }}\right)^{(1-\alpha)}\left(c_{\mathrm{i}}^{\text {surf }}\right)^{\alpha} \\
\times\left[\exp \left(\frac{0.5 F}{R T} \eta_{\mathrm{i}}\right)-\exp \left(-\frac{0.5 F}{R T} \eta_{\mathrm{i}}\right)\right], \\
\eta_{\mathrm{i}}=\phi_{\mathrm{si}}-\phi_{\mathrm{ei}}-U_{\mathrm{i} .}
\end{gathered}
$$

Here, the subscript "i" denotes either "s" or "p" for PE and " $n$ " for NE. At the PE surface, the properties corresponding to the shell are denoted with the subscript "s". PE variables in the core are denoted with the subscript " $p$ " and correspond to properties of the nondegraded active material. Notably, the BV kinetics is applied on the particle surface i.e. at $r=R_{\mathrm{p}}$ for PE and at $r=R_{\mathrm{n}}$ for NE. $k_{0 \mathrm{i}}$ represents the electrochemical reaction rate constant at the electrode"i"/electrolyte interface, $\alpha$ represents the charge transfer coefficient, $c_{\mathrm{e}}$ is the Li-ion concentration in the electrolyte (solution phase), $c_{\mathrm{i}}^{\max }$ is the maximum Li-ion concentration in the electrode- " $\mathrm{i}$ " particle (solid phase), $c_{\mathrm{i}}^{\text {surf }}$ is the Li-ion concentration at the electrode-" $\mathrm{i}$ " particle surface, $R$ is the ideal gas law constant, $T$ denotes the temperature of the cell, and $\eta_{\mathrm{i}}$ is the overpotential. The overpotential at each electrode can be defined in terms of solid-phase potential $\left(\phi_{\mathrm{si}}\right)$, solution-phase potential $\left(\phi_{\mathrm{ei}}\right)$, and open-circuit potential (OCP, $\left.U_{\mathrm{i}}\right)$, related as shown in Eq. 19.

The effect of the electrolyte phase on the cell voltage is modelled via a resistor as, $\phi_{\mathrm{ep}}-\phi_{\mathrm{en}}=I_{\mathrm{app}} R_{\mathrm{e}}$, where $R_{\mathrm{e}}$ is the electrolyte resistance. $^{55}$ The difference between the solid phase electrode potentials defines the cell voltage $\left(V_{\text {cell }}\right)$ as, $\phi_{\text {sp }}-\phi_{\text {sn }}=V_{\text {cell. }}$ Using Eq. 19 and the electrolyte as a resistor simplification, the cell voltage is obtained as, $V_{\text {cell }}=U_{\mathrm{p}}-U_{\mathrm{n}}+\eta_{\mathrm{p}}-\eta_{\mathrm{n}}+I_{\text {app }} R_{\mathrm{e}}$. The Eq. 18 can be solved for $\eta_{\mathrm{i}}$ to obtain an explicit expression for cell voltage as,

$$
\begin{aligned}
V_{\text {cell }}= & U_{\mathrm{p}}\left(x_{\mathrm{p}}^{\text {surf }}\right)-U_{\mathrm{n}}\left(x_{\mathrm{n}}^{\text {surf }}\right)+\frac{2 R T}{F} \\
& \times\left[\ln \left(\frac{\sqrt{m_{\mathrm{p}}^{2}+4}+m_{\mathrm{p}}}{2}\right)+\ln \left(\frac{\sqrt{m_{\mathrm{n}}^{2}+4}+m_{\mathrm{n}}}{2}\right)\right] \\
& +I_{\mathrm{app}} R_{\mathrm{e}}, \\
m_{\mathrm{p}}= & I_{\mathrm{app}}\left[F A_{\mathrm{p}} k_{0 \mathrm{p}} c_{\mathrm{e}}^{0.5} c_{\mathrm{p}}^{\max }\left(1-x_{\mathrm{s}}^{\text {surf }}\right)^{0.5}\left(x_{\mathrm{s}}^{\text {surf }}\right)^{0.5}\right]^{-1}, \\
m_{\mathrm{n}}= & I_{\text {app }}\left[F A_{\mathrm{n}} k_{0 \mathrm{n}} c_{\mathrm{e}}^{0.5} c_{\mathrm{n}}^{\max }\left(1-x_{\mathrm{n}}^{\text {surf }}\right)^{0.5}\left(x_{\mathrm{n}}^{\text {surf }}\right)^{0.5}\right]^{-1}
\end{aligned}
$$

Here, the variable $x_{\mathrm{i}}^{\text {surf }}$ denotes the surface stoichiometry at each particle boundary which can be defined as, $x_{\mathrm{i}}^{\text {surf }}=c_{\mathrm{i}}^{\text {surf }} / c_{\mathrm{i}}^{\text {max }}$. The variation of $U_{\mathrm{i}}$ with $x_{\mathrm{i}}$ for each electrode is provided in Figs. S1a and $\mathrm{S} 1 \mathrm{~b}$ of Electronic supplementary information (ESI) (available online at stacks.iop.org/JES/168/020509/mmedia).

Thermal model.-Cell temperature plays an important role in battery degradation in general, and for the degradation of NMC811 $\mathrm{PE}$ in particular. Thus, the proposed mSPM includes a lumped thermal model. Spatial temperature inhomogeneities across the cell are neglected in this formulation. The change in the cell temperature $(T)$ with time $(t)$ is governed by the general energy balance as,

$$
\begin{aligned}
\rho \nu C_{\mathrm{p}} \dot{T}= & I_{\mathrm{app}} T\left[U_{\mathrm{p}, T}\left(x_{\mathrm{p}}^{\text {surf }}\right)-U_{\mathrm{n}, T}\left(x_{\mathrm{n}}^{\text {surf }}\right)\right] \\
& +I_{\mathrm{app}}\left(\eta_{\mathrm{p}}-\eta_{\mathrm{n}}+I_{\mathrm{app}} R_{\mathrm{e}}\right)-h A_{\mathrm{c}}\left(T-T_{\mathrm{amb}}\right) .
\end{aligned}
$$

Here, $\rho$ is the density, $v$ denotes the volume, $C_{\mathrm{p}}$ is the specific heat capacity, and $A_{\mathrm{c}}$ is the surface area of the cell. The parameter, $h$ denotes the heat transfer coefficient between the cell and the surroundings. The initial cell temperature is assumed to be equal to the ambient temperature $\left(T_{\mathrm{amb}}\right)$,

$$
\left.T\right|_{t=0}=T_{\mathrm{amb}} .
$$

The first right-hand side term of Eq. 23 represents the reversible heat generation, due to change in entropy, while the second righthand side term represents the irreversible heat generation due to reaction kinetics and Ohmic losses in the electrolyte. The third term on the right-hand side represents the cooling of the cell by exchanging heat via convection with the surroundings. Radiative heat loss is ignored.

The diffusivities, electrochemical and chemical reaction rate constants, OCPs, and electrolyte resistance are all functions of temperature, via the following relations,

$$
\begin{gathered}
D_{\mathrm{i}}(T)=D_{\mathrm{i}}^{\text {ref }} \exp \left[\frac{E a_{\mathrm{di}}}{R}\left(\frac{1}{T_{\text {ref }}}-\frac{1}{T}\right)\right],(\mathrm{i}=\mathrm{p}, \mathrm{s}, \mathrm{n}, \mathrm{o}) \\
k_{0 \mathrm{i}}(T)=k_{0 \mathrm{i}}^{\text {ref }} \exp \left[\frac{\left.E a_{\mathrm{k} 0 \mathrm{i}}\left(\frac{1}{R}-\frac{1}{T_{\text {ref }}}\right)\right],(\mathrm{i}=\mathrm{p}, \mathrm{n})}{k_{\mathrm{j}}(T)}=k_{\mathrm{j}}^{\text {ref }} \exp \left[\frac{E a_{\mathrm{kj}}}{R}\left(\frac{1}{T_{\text {ref }}}-\frac{1}{T}\right)\right],(\mathrm{j}=1,2)\right. \\
U_{\mathrm{i}}\left(x_{\mathrm{i}}^{\text {surf }}, T\right)=U_{\mathrm{i}}\left(x_{\mathrm{i}}^{\text {surf }}, T_{\text {ref }}\right)+\left.U_{\mathrm{i}, T}\right|_{x_{\mathrm{i}}^{\text {surf }}, T_{\text {ref }}}\left(T-T_{\text {ref }}\right),(\mathrm{i}=\mathrm{p}, \mathrm{n})
\end{gathered}
$$




$$
\begin{aligned}
& R_{\mathrm{e}}\left(I_{\mathrm{app}}, T\right)=\theta_{1}+\theta_{2}\left(T-T_{\mathrm{amb}}\right), \\
& \theta_{1}=R_{\mathrm{e}}\left(0, T_{\mathrm{amb}}\right)+\left.R_{\mathrm{e}, I_{\mathrm{app}}}\right|_{0, T_{\mathrm{amb}}} I_{\mathrm{app}}, \\
& \theta_{2}=\left.R_{\mathrm{e}, T}\right|_{0, T_{\mathrm{amb}}}+\left.R_{\mathrm{e}, I_{\mathrm{app}} T}\right|_{0, T_{\mathrm{amb}}} I_{\mathrm{app}} .
\end{aligned}
$$

The diffusivities and reaction rate constants stated in Eqs. 25-27 $7^{55,62}$ follow an Arrhenius' relationship whereas, the OCP and electrolyte resistance temperature dependencies are obtained using Taylor's series expansion as stated in Eqs. 28-29. ${ }^{55}$ Here, $T_{\text {ref }}$ is the reference temperature. The constants $D_{\mathrm{i}}^{\text {ref }}, k_{0 \mathrm{i}}^{\text {ref }}$, and $k_{\mathrm{j}}^{\text {ref }}$ are the diffusivity, electrochemical reaction rate, and chemical reaction rate at the reference temperature, respectively. The notations, $E a_{\mathrm{di}}, E a_{\mathrm{k} 0 \mathrm{i}}$, and $E a_{\mathrm{kj}}$ denote activation energies for diffusivity, electrochemical reaction rate, and chemical reaction rate, respectively. The variation of $U_{\mathrm{i}, T}$ with $x_{\mathrm{i}}$ for each electrode is provided in Figs. S1c and S1d of ESI. The parameters, $\theta_{1}$ and $\theta_{2}$ are fitting parameters obtained from Eq. 29.

\section{Numerical Implementation}

Mapping.-The coupled governing equations, boundary and initial conditions, and cell temperature equations are made nondimensional and the dimensionless equations are presented in Appendix B. Henceforth, the variable radius $(r)$ of the PE and NE is denoted as $r_{\mathrm{p}}$ and $r_{\mathrm{n}}$, respectively. To solve the set of coupled non-dimensional equations [Eqs. B.1-B.12], each computational domain (i.e. core, $r_{\mathrm{p}} \in(0, s)$, and shell, $\left.r_{\mathrm{p}} \in\left(s, R_{\mathrm{p}}\right)\right)$ is mapped onto a one-dimensional space $(0,1)$ with the help of the transformations, $\eta=r_{\mathrm{p}} / s$, for the core and $\chi=\left(r_{\mathrm{p}}-s\right) /(1-s)$ for the shell. The transformed set of coupled equations [Eqs. C.1-C.12] are shown in Appendix C. The non-dimensional equations [Eqs. B.13-B.16] for the NE domain, $r_{\mathrm{n}} \in\left(0, R_{\mathrm{n}}\right)$, are already mapped into the transformed $(0,1)$ space.

Implementation.-The transformed partial differential equations (PDEs) [Eqs. C.1-C.12 and B.13-B.16] for three different computational domains, core, shell, and NE, are discretized in space using central differencing scheme with a half-node interpolation. The resulting ordinary differential equations (ODEs) are integrated over time by employing the adaptive Runge-Kutta method with orders 4 and 5 mixed (RK45). The set of non-dimensional temperature equations [Eqs. B.17-B.18] are treated similarly. For most of the simulations performed, it was found that 50 points in space for each computational domain is sufficient for satisfactory convergence. All the numerical simulations have been performed using the commercial software package MATLAB (v. R2018a). The subroutine "ode45" is employed to implement the RK45 method for timemarching solutions. The model is capable of predicting the results 10 times faster than the experimental time.

The time-dependent concentration profiles $\left(c_{\mathrm{p}}, c_{\mathrm{s}}, c_{\mathrm{o}}\right.$, and $\left.c_{\mathrm{n}}\right)$ and the time-dependent cell temperature $\left(T^{*}\right)$ is obtained employing the numerical scheme outlined above. After making the variables non-dimensional, surface concentrations are equivalent to surface stoichiometries $\left(x_{\mathrm{p}}^{\text {surf }}=c_{\mathrm{s}}^{\text {surf }} / c_{\mathrm{p}}^{\max }\right.$ and $\left.x_{\mathrm{n}}^{\text {surf }}=c_{\mathrm{n}}^{\text {surf }} / c_{\mathrm{n}}^{\max }\right)$. The surface stoichiometries together with dimensional cell-temperature $\left(T=T^{*} T_{\text {ref }}\right)$ are used to obtain cell-voltage,

$$
\begin{aligned}
V_{\text {cell }}= & U_{\mathrm{p}}\left(x_{\mathrm{p}}^{\text {surf }}, T_{\text {ref }}\right)-U_{\mathrm{n}}\left(x_{\mathrm{n}}^{\text {surf }}, T_{\text {ref }}\right) \\
& +\left(\left.U_{\mathrm{p}, T}\right|_{x_{\mathrm{p}}^{\text {surf }}, T_{\text {ref }}}-\left.U_{\mathrm{n}, T}\right|_{x_{\mathrm{n}}^{\text {surf }}, T_{\text {ref }}}\right)\left(T-T_{\text {ref }}\right) \\
& +\frac{2 R T}{F}\left[\ln \left(\sqrt{m_{\mathrm{p}}^{2}+4}+m_{\mathrm{p}} / 2\right)\right. \\
& \left.+\ln \left(\sqrt{m_{\mathrm{n}}^{2}+4}+m_{\mathrm{n}} / 2\right)\right] \\
& +I_{\mathrm{app}}\left[\theta_{1}+\theta_{2}\left(T-T_{\mathrm{amb}}\right)\right] .
\end{aligned}
$$

Equation 30 is obtained from Eqs. 18-19 and including temperature dependencies from Eqs. 26, 28-29.
Validation.-We have validated our model with existing literature results of thermally coupled SPM for predicting the beginning of life (BOL) behaviour of a Li-ion cell. ${ }^{55}$ In the literature the set of model equations were solved analytically using the eigenfunction expansion method and then validated with corresponding experimental results. In our presented model (mSPM) we have set $s=1$ and $\dot{s}=0$ to obtain BOL equations and solved using the above stated numerical methodology using the same parameter values as in Ref. 55. The validation results are shown in Fig. S2 of ESI. We have shown that the variation in cell voltage $\left(V_{\text {cell }}\right)$ and temperature $(T)$ with capacity (Cap) obtained using MSPM are in excellent agreement with those in the literature.

Parameterisation.-The Li-ion cell considered here is a commercial 3.35 Ah Li-ion battery with NMC811/SiC chemistry. The parameter values for this cell are taken mostly from the available literature. ${ }^{58} \mathrm{~A}$ few of the parameters are empirically fitted according to the BOL simulation results obtained from our simulations and the existing experimental behaviour of the particular cell. The parametrisation results are presented in Fig. S3 of ESI. The BOL parameters are listed in Table I. Table II presents the standard values of the degradation parameters considered for the simulations and the variation considered for these parameters are mentioned in the figure captions. Due to the lack of experimental results and relevant molecular-scale information, a wide range of values is considered for most of the degradation parameters. The effect of the value and interplay of degradation parameters on cell behaviour is the subject of the next section.

\section{Results and Discussion}

Several studies have suggested that layered structures of PEs $\left(\mathrm{Li}_{\mathrm{y}} \mathrm{MO}_{2}, \mathrm{M}\right.$ can be $\mathrm{Co}, \mathrm{Mn}, \mathrm{Ni}$, or any combination of these transition metals) are thermodynamically unstable whenever $y \leqslant 0.5$, which limits their reversible capacity to $50 \%$ of their theoretical capacity. ${ }^{11,27-30}$ For high-nickel NMC materials a Licontent below $y \leqslant 0.4$ causes a phase transition. ${ }^{11,22}$ The critical Liion concentration $\left(c^{*}\right)$ in the present study is set to $c^{*} \leqslant 0.4$. The interplay between the chemical reaction rate for the formation of the shell and the [O]-diffusivity through the shell will determine the rate of shell formation. The increase in the shell thickness can cause both power and capacity fade by slowing down Li-ion diffusion. Considering the above, we have focused on exploring the influences of the [O]-diffusivity $\left(D_{\mathrm{o}}\right)$ through the shell, reaction rate constants $\left(K_{1}\right.$ and $\left.K_{2}\right)$, Li-ion-diffusivity $\left(D_{\mathrm{s}}\right)$ through the shell, amount of Liions lost $(\phi)$ in shell formation, and initial shell thickness $\left(R_{\mathrm{p}}-s_{\mathrm{i}}\right)$ on the evolution of the cell behaviour to uncover the physics of this degradation mechanism.

All the simulations presented in this study have considered: $(i)$ the cell is being charged from $2.5 \mathrm{~V}(0 \%$ SoC, start of charging) to $4.2 \mathrm{~V}$ (100\% SoC, end of charging) using a constant current of $1.675 \mathrm{~A}$, (ii) the PE has an initial shell thickness $s_{\mathrm{i}}$, and (iii) the phase transition reaction (Eq. 12) occurs whenever the Li-ion concentration $\left(c_{\mathrm{p}}\right)$ at the core-shell interface $(s)$ drops below the critical Li-ion concentration $\left(c^{*}\right)$. All simulation results are presented using non-dimensional variables (refer Appendix B), except cell voltage $\left(V_{\text {cell }}\right)$ and capacity $(\mathrm{Cap})$.

Concentration profiles.-mSPM predictions during a constant current charging are shown in Fig. 2, with an emphasis on the time evolution of concentration profiles in the PE and their effect on the shell thickness. Following the experimental observations (as discussed previously in the "Theoretical Formulation" section) the PE has an initial shell thickness as shown schematically by case A of Fig. 2a. The shell thickness increases whenever $c_{\mathrm{p}}$ at $s$ is below $c^{*}$ following the reaction kinetics of Eq. 13. The end of charge crosssectional morphology of the PE is presented by case B of Fig. 2a. Figure $2 \mathrm{~b}$ shows the variation of Li-ion concentrations $\left(c_{\mathrm{p}}\right.$ and $\left.c_{\mathrm{s}}\right)$ with the PE particle radius, $r_{\mathrm{n}}$. Curves 1-11 represent the evolution 
Table I. Dimensional values used for the mSPM simulations. All the values are taken from an existing work. ${ }^{58}$ The superscript "c" denotes the calculated values whereas the superscript "e" denotes "estimated" values empirically fitted with the experimentally observed results reported in the same literature ${ }^{58}$ from where all the other values are taken.

3.35 Ah NMC811/SiC (INR18650-MJ1, LG Chem Cell) Li-ion battery parameters

\begin{tabular}{|c|c|c|c|c|}
\hline \multicolumn{2}{|c|}{ Variables (Unit) } & \multicolumn{2}{|l|}{$\begin{array}{l}\text { Positive Electrode (NMC811) } \\
\qquad(\mathrm{i}=\mathrm{p})\end{array}$} & $\begin{array}{l}\text { Negative Electrode }(\mathrm{SiC}) \\
\qquad(\mathrm{i}=\mathrm{n})\end{array}$ \\
\hline \multicolumn{2}{|c|}{$V_{\mathrm{i}}\left(\mathrm{m}^{3}\right)$} & $4.7 \times 10^{-6}$ & & $6.2 \times 10^{-6}$ \\
\hline \multicolumn{2}{|c|}{$\varepsilon_{\mathrm{i}}(\%)$} & 74.5 & & 69.4 \\
\hline \multicolumn{2}{|c|}{$R_{\mathrm{p}}(\mu \mathrm{m})$} & 3.8 & & 6.1 \\
\hline \multicolumn{2}{|c|}{$c_{\mathrm{i}}^{\max }\left(\mathrm{mol} \mathrm{m}^{-3}\right)$} & $49340^{\mathrm{c}}$ & & $34257^{\mathrm{c}}$ \\
\hline Stoichiometry $\left(x_{\mathrm{i}}\right)$ & $100 \%$ SoC & 0.222 & & 0.852 \\
\hline & $0 \% \mathrm{SoC}$ & 0.942 & & 0.002 \\
\hline \multicolumn{2}{|c|}{$D_{\mathrm{i}}^{\mathrm{ref}}\left(\mathrm{m}^{2} \mathrm{~s}^{-1}\right)$} & $1.0 \times 10^{-14 \mathrm{e}}$ & & $1.0 \times 10^{-14 \mathrm{e}}$ \\
\hline \multicolumn{2}{|c|}{$k_{0 \mathrm{i}}^{\mathrm{ref}}\left(\mathrm{m}^{2.5} \mathrm{~mol}^{-0.5} \mathrm{~s}^{-1}\right)$} & $1.0 \times 10^{-11 \mathrm{e}}$ & & $3.2 \times 10^{-11 \mathrm{e}}$ \\
\hline \multicolumn{2}{|c|}{$E a_{\mathrm{di}} / R(\mathrm{~K})$} & 1200 & & 1200 \\
\hline \multicolumn{2}{|c|}{$E a_{\mathrm{k} 0 \mathrm{i}} / R(\mathrm{~K})$} & 3600 & & 3600 \\
\hline \multicolumn{2}{|c|}{$c_{\mathrm{e}}\left(\mathrm{mol} \mathrm{m}^{-3}\right)$} & & 1000 & \\
\hline \multicolumn{2}{|c|}{$\alpha$} & & 0.5 & \\
\hline \multicolumn{2}{|c|}{$F\left(\mathrm{C} \mathrm{mol}^{-1}\right)$} & & 96487 & \\
\hline \multicolumn{2}{|c|}{$R\left(\mathrm{~J} \mathrm{~mol}^{-1} \mathrm{~K}^{-1}\right)$} & & 8.3143 & \\
\hline \multicolumn{2}{|c|}{$\rho\left(\mathrm{kg} \mathrm{m}^{-3}\right)$} & & 2761.7 & \\
\hline \multicolumn{2}{|c|}{$v\left(\mathrm{~m}^{3}\right)$} & & $16.5 \times 10^{-6}$ & \\
\hline \multicolumn{2}{|c|}{$C_{\mathrm{p}}\left(\mathrm{J} \mathrm{kg}^{-1} \mathrm{~K}^{-1}\right)$} & & 918.8 & \\
\hline \multicolumn{2}{|c|}{$h A_{\mathrm{c}}\left(\mathrm{J} \mathrm{s}^{-1} \mathrm{~K}^{-1}\right)$} & & 0.093 & \\
\hline \multicolumn{2}{|c|}{$T_{\text {ref }}(\mathrm{K})$} & & 298 & \\
\hline \multicolumn{2}{|c|}{$I_{\text {app }}(\mathrm{A})$} & & $3.35(1.0 \mathrm{C})$ & \\
\hline
\end{tabular}

The maximum concentrations of Li-ions $\left(c_{\mathrm{i}}^{\max }\right)$ in the positive and negative electrodes at the beginning of life are calculated as, $c_{\mathrm{i}}^{\text {max }}=\frac{\text { Capacity of the cell }}{\Delta \mathrm{SoC} \times \varepsilon_{\mathrm{i}} \times V_{\mathrm{i}} \times F},{ }^{6}$ where $\triangle \mathrm{SoC}$ represents the change in SoC.

For NE, $c_{\mathrm{n}}^{\max }=\frac{3.35 \times 3600}{(0.852-0.002) \times 0.694 \times 6.2 \times 10^{-6} \times 96487}=34257 \mathrm{~mol} \mathrm{~m}^{-3}$ and
For PE, $c_{\mathrm{p}}^{\max }=\frac{3.35 \times 3600}{(0.942-0.222) \times 0.745 \times 4.7 \times 10^{-6} \times 96487}=49340 \mathrm{~mol} \mathrm{~m}^{-3}$.

Table II. Estimated values used for the shell region and side reaction parameters for the mSPM simulations.

\begin{tabular}{lc} 
Variables $($ Unit $)$ & Value \\
\hline$D_{\mathrm{s}}^{\text {ref }}\left(\mathrm{m}^{2} \mathrm{~s}^{-1}\right)$ & $1.0 \times 10^{-15}$ \\
$D_{\mathrm{o}}^{\text {ref }}\left(\mathrm{m}^{2} \mathrm{~s}^{-1}\right)$ & $1.0 \times 10^{-17}$ \\
$E a_{\mathrm{ds}} / R(\mathrm{~K})$ & 1200 \\
$E a_{\mathrm{do}} / R(\mathrm{~K})$ & 1200 \\
$K_{1}$ & 0.1 \\
$K_{2}$ & 0.01 \\
$E a_{\mathrm{kj}} / R(\mathrm{~K})(\mathrm{j}=1,2)$ & 3600 \\
$\phi$ & 0.7
\end{tabular}

of the concentration profiles with time $(t)$. An effective concentration gradient between the centre and surface of the particle creates the necessary driving force for the Li-ions to diffuse out from the centre of the particle to the particle surface. However, the Li-ion diffusivity in the shell region is lesser $\left(D_{\mathrm{s}}<D_{\mathrm{p}}\right)$ than the core. The changeover of the diffusivities is observed in the concentration profiles by the change of slopes of each curve as represented by solid and broken lines in Fig. $2 b$.

The curves 1-7 show the concentration profiles until the Li-ion concentration $\left(c_{\mathrm{p}}\right)$ at the core-shell interface $(s)$ reaches the critical concentration $\left(c^{*}\right)$. During charging of the cell, until this point of time, the shell thickness of the PE remains the same as schematically shown by case A. Once, $c_{\mathrm{p}}$ at $s$ falls below $c^{*}$, the phase transition reaction begins which eventually increases the shell thickness (by forming $\mathrm{Li}_{\mathrm{y}} \mathrm{MO}$ ), as shown by the curves $8-11$. The formation of the shell also reduces the recyclable Li-ions present in the PE. The Li-ions converted into $\mathrm{Li}_{\mathrm{y}} \mathrm{MO}$ to produce the newly formed shell do not participate in the intercalation-deintercalation process further, which therefore results in a loss of Li-ion inventory (LLI). The inception of the chemical reaction is marked by curve 8 as a clear change in curvature is observed between the curves 7 and 8 . The change in curvature between the curves 7 and 8 is trigger by the amount of Li-ions lost in the shell formation by considering $\phi=0.7$, where, $\phi$ is the measure of LLI as defined previously. It is important to note we would not expect the core to shrink this rapidly in a single charging event for a normal battery, it has only been accelerated here to make the outcome more obvious.

A closer observation of the core-shell interfacial positions of the curves 7-11 reveals the shifting of the core-shell interface (circular symbols) towards the centre of the PE particle which indicates the increase in the shell thickness. The shifting of the interfacial position is identified and marked in Fig. 2b which is magnified in Fig. 2c for a clear demonstration of the increase in the shell thickness with time. Curve 11 shows the concentration profile obtained from the simulations at the end of charging and the consequent shell thickness of the PE particle can be schematically shown by case B. Fig. $2 d$ shows the variation of shell thickness $\left(R_{\mathrm{p}}-s\right)$ with time. Initially, the shell thickness remains constant (initial shell thickness remains persistent as shown by case A) till $c_{\mathrm{p}}$ at $s$ reduces below $c^{*}$. After that, there is a linear increase in shell thickness with time. Consequently, the PE particle consists of a thicker shell at the end of charging (case B) as compared to the start of charging (case A). The variation in the shell thickness profile shown in plot (d) confirms that the simulations can capture the dynamics of the shell growth. We expect the onset of the reaction may need to be described by a 

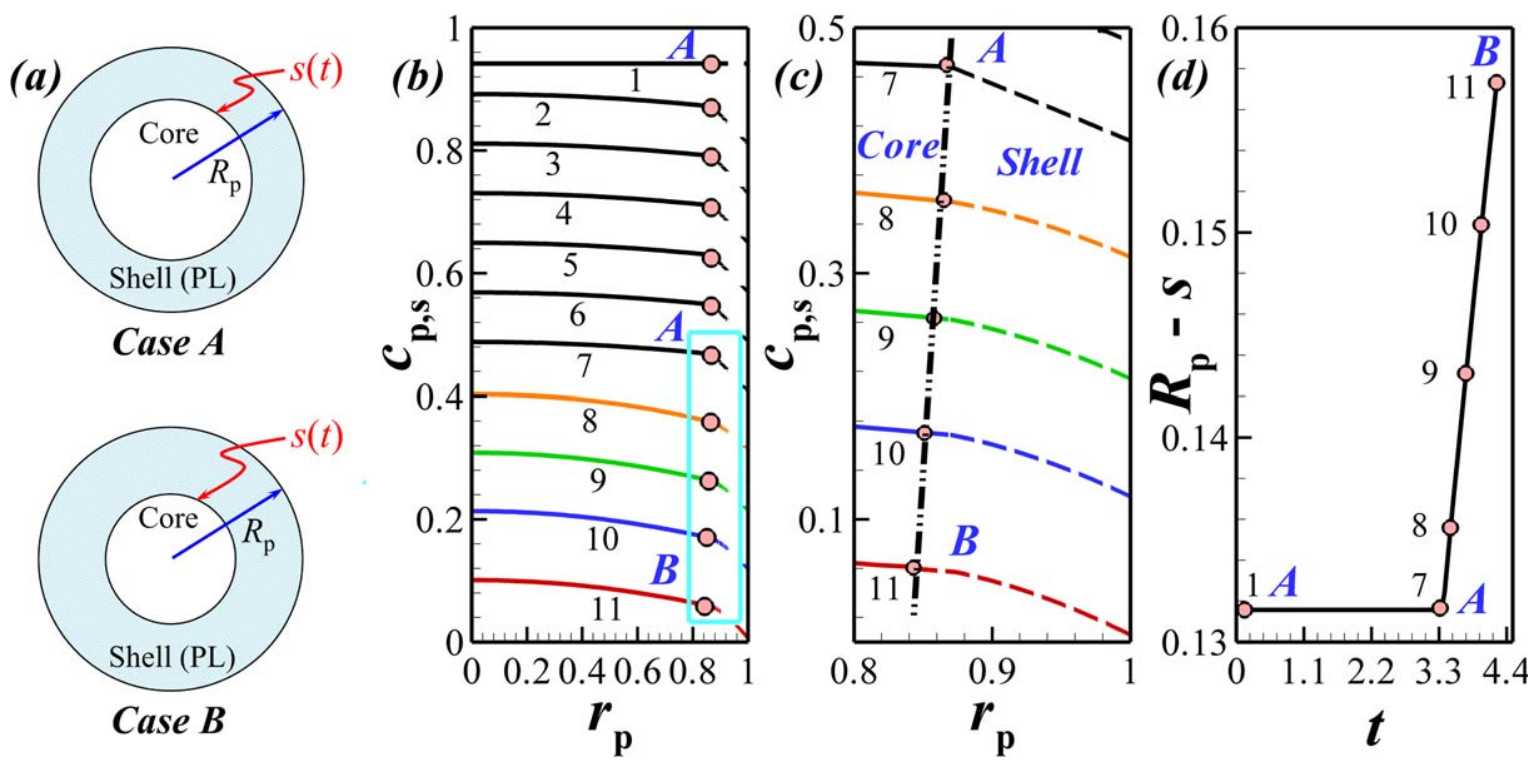

Figure 2. Positive electrode (PE) core-shell concentration profiles and shell thickness predicted by mSPM simulations. Plot (a) schematically shows the initial (Case A) and end of charge (Case B) shell thickness of the PE. Plot (b) shows the variation of Li-ion concentrations $\left(c_{\mathrm{p}}\right.$ and $\left.c_{\mathrm{s}}\right)$ across the PE particle radius $\left(r_{\mathrm{p}}\right)$. Solid and broken lines represent concentration variation of Li-ions in the core $\left(c_{\mathrm{p}}\right.$ vs $\left.r_{\mathrm{p}}\right)$ and shell $\left(c_{\mathrm{s}}\right.$ vs $\left.r_{\mathrm{p}}\right)$, respectively. Curves 1-11 in plot (b) correspond to the concentration profiles at times, $t=0,0.45,0.95,1.45,1.95,2.44,2.94,3.44,3.69,3.94$, and 4.34 . Curve 8 marks the inception of shell growth with a change in the curvature of the concentration profiles. The boxed region in the plot (b) is magnified as plot (c) to demonstrate the increase in the shell thickness with time. The circular symbols in both plots (b) and (c) indicate the position of the core-shell interface. Plot (d) shows the variation of shell thickness $\left(R_{\mathrm{p}}-s\right)$ with $t$. These results correspond to the following parameter values: $s_{\mathrm{i}}=0.87, T_{\mathrm{amb}}=298 \mathrm{~K}, I_{\mathrm{app}}=\mathrm{C} / 2$, and $c^{*}=0.4$. The other necessary parameters are listed in Tables I and II.

more complex onset function, but we have chosen the simplest function possible for this paper to demonstrate the principle. It is important to note that the passivation layer formation and lattice oxygen, [O], evolution reaction is a chemical reaction, not electrochemical, therefore it will occur whenever $c_{\mathrm{p}}$ at $s$ is below $c^{*}$ regardless of whether the current is flowing or not. Therefore, this model is capable of retrieving PE degradation during cycling and calendar ageing.

As described earlier, the chemical reaction responsible for the structural changes of PE produces $[\mathrm{O}]$ at the core-shell interface $(s)$. Figure $3 \mathrm{a}$ shows the $[\mathrm{O}]$-concentration profiles with time. The sudden increase in $c_{\mathrm{o}}$ at $s$ is because of the inception of the chemical reaction as shown by curves 7 and 8 in the plot (a). Curves $8-11$ shows the gradual increase in $c_{\mathrm{o}}$ at $s$ with shell thickness growth. The zeroconcentration boundary condition at the PE particle boundary creates the driving force for [O] to diffuse out. Recent experimental studies show that the amount of gas $\left(\mathrm{O}_{2}, \mathrm{CO}_{2}, \mathrm{CO}\right)$ produced increases with an increase in the spinel/rock-salt layer (i.e. shell) thickness. The reason behind the evolution of these gases is the reaction of reactive [O] with the electrolyte when the cell is charged to between 4.0-4.5 V. The results obtained from the mSPM presented here could be used to reproduce the same observation, ${ }^{22,24,25}$ if additional equations to describe the $[\mathrm{O}]$ reacting with electrolyte species were to be included. Figures $2 \mathrm{~d}$ and $3 \mathrm{a}$ distinctly show the growth of shell thickness $\left(R_{\mathrm{p}}-s\right)$ and increase in [O]-concentration $\left(c_{\mathrm{o}}\right)$ at the core-shell interface $(s)$ happen simultaneously with time. Figure $3 \mathrm{~b}$ shows the time-dependent concentration profile of Li-ions, as they diffuse in the NE during charging. As this model does not include degradation at the $\mathrm{NE}$, the Li-ion concentration profiles are those expected for a beginning of life (BOL) NE.

Figure $3 \mathrm{c}$ shows the cell temperature variation with time. As shown in the figure, the cell temperature variation can be divided into four regions. In the beginning, the cell temperature increases to reach a plateau and then increases sharply; with further charging the cell temperature drops slightly to go through a minimum and starts to increase rapidly again. The trajectory of the temperature evolution can be explained using Eq. 23 and the entropy change coefficient profiles $\left(U_{\mathrm{i}, T}\right.$ vs $\left.x_{\mathrm{i}}\right)$ of each electrode (shown in Figs. S1c and S1d of ESI). The initial electrode stoichiometries $\left(x_{\mathrm{p}}=0.942, x_{\mathrm{n}}=0.002\right)$ before charging are such that, during the initial stage of charging, $U_{\mathrm{p}, T}$ increases sharply, while $U_{\mathrm{n}, T}$ remains almost flat, causing an initial increase in cell temperature according to the first term of the right-hand side of Eq. 23. As the charging continues both $U_{\mathrm{p}, T}$ and $U_{\mathrm{n}, T}$ goes through few local maxima and minima which cause sequential plateau, a sharp increase, and a drop (ambient cooling also reduce cell temperature) in the temperature profile. At the end of charging, with the increase in shell thickness increases the overpotential (decrease in $c_{\mathrm{s}}^{\text {surf }}$ increases $\eta_{\mathrm{p}}$ ). Accordingly, the irreversible heat term (second term of the right-hand side of Eq. 23) becomes significantly positive together with the reversible heat term. Thus, the cell temperature increases rapidly at the end of charge, by the joint effect of reversible and irreversible heat sources. The shell formation increases the resistance of the cell to increase the cell temperature. Figures 2 and 3 uncover the shell and [O]-formation dynamics and their influence on the Li-ion concentration profiles of $\mathrm{PE}$ and temperature of the cell.

Capacity fade.-The influence of shell formation and [O]evolution on the performance of the cell is investigated in a step by step manner via simulated cell voltage for a $\mathrm{C} / 2$ charge, as shown in Fig. 4. The capacity of the cell is defined as,

$$
\text { Cap }=\frac{1}{3600} \int_{0}^{t_{\mathrm{f}}}\left|I_{a p p}\right| d t
$$

Here, $t_{\mathrm{f}}$ is the time at the end of charge. Figure 4a shows four possible hypothetical PE configurations while the NE particle is always in the BOL state. The cell voltage-capacity curves shown in Fig. 4b are obtained from Eqs. 30 and 31. Case A shows a BOL SPM model, where the PE particle has no shell. The cell voltage $\left(V_{\text {cell }}\right)$ variation with the capacity ( $\mathrm{Cap}$ ) of the cell for case A is shown by curve A in Fig. 4b. We consider the capacity obtained in this case as the baseline $100 \%$ capacity of the cell. Inclusion of a shell layer with 

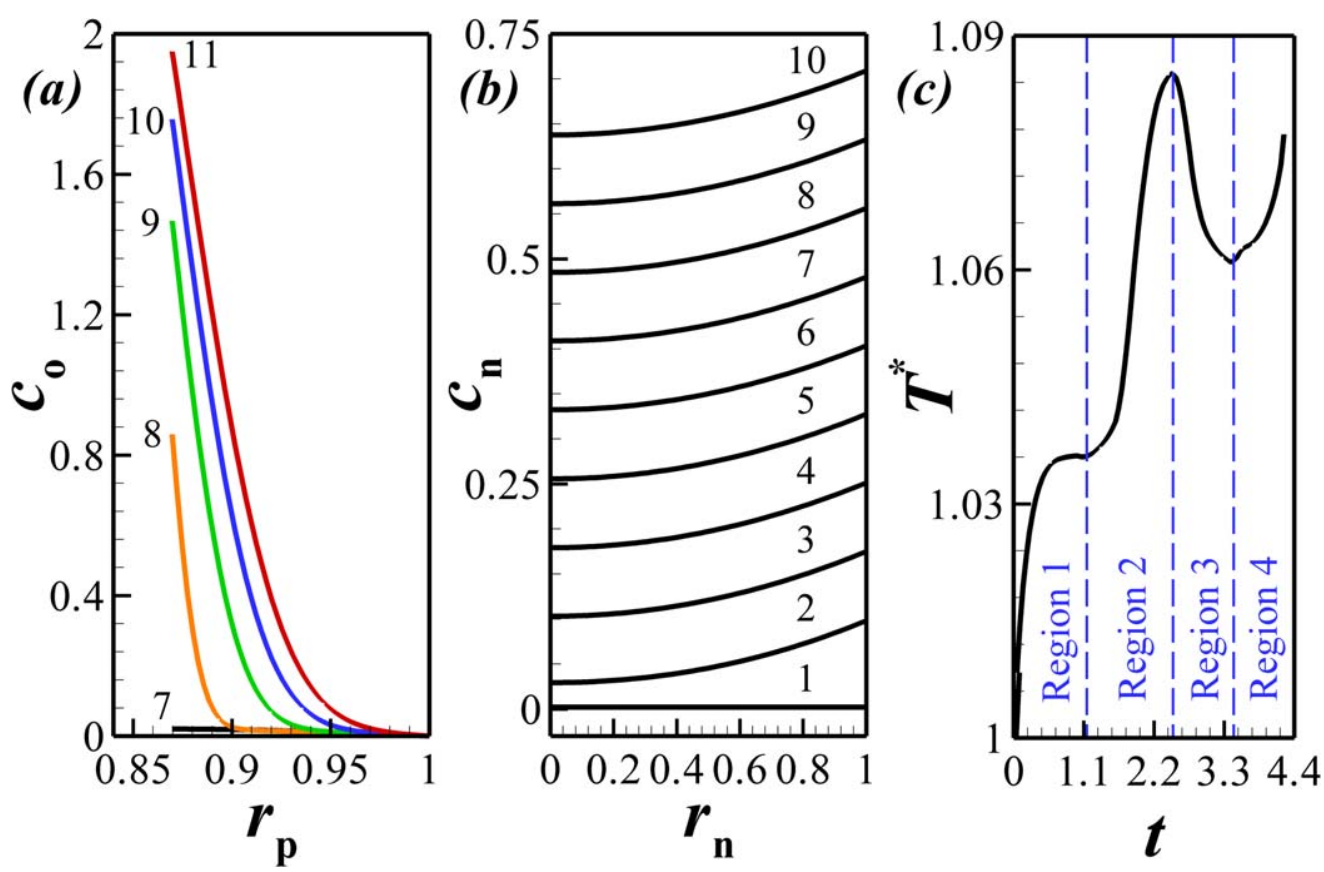

Figure 3. [O]-concentration profiles in the PE, Li-ion concentration profiles in the NE, and the cell temperature variation obtained from mSPM simulations. Plot (a) shows the variation of [O]-concentration $\left(c_{\mathrm{o}}\right)$ across PE particle radius $\left(r_{\mathrm{p}}\right)$ within the shell once the shell starts growing. Curves 7-11 show the evolution of [O]-concentration profile with time, for the same time instances at curves 7-11 are obtained in Fig. 2b. Plot (b) shows the variation of Li-ion concentrations $\left(c_{\mathrm{n}}\right)$ across NE particle radius $\left(r_{\mathrm{n}}\right)$. Curves $1-10$ correspond to the concentration profiles at times, $t=0,0.4,0.85,1.3,1.75,2.19,2.64,3.09,3.54$, and 4.0 . Plot $(\mathrm{c})$ shows the time evolution of cell temperature $\left(T^{*}\right)$. The parameters used for the simulations are the same as Fig. 2. The other parameters required of the simulations are listed in Tables I and II.
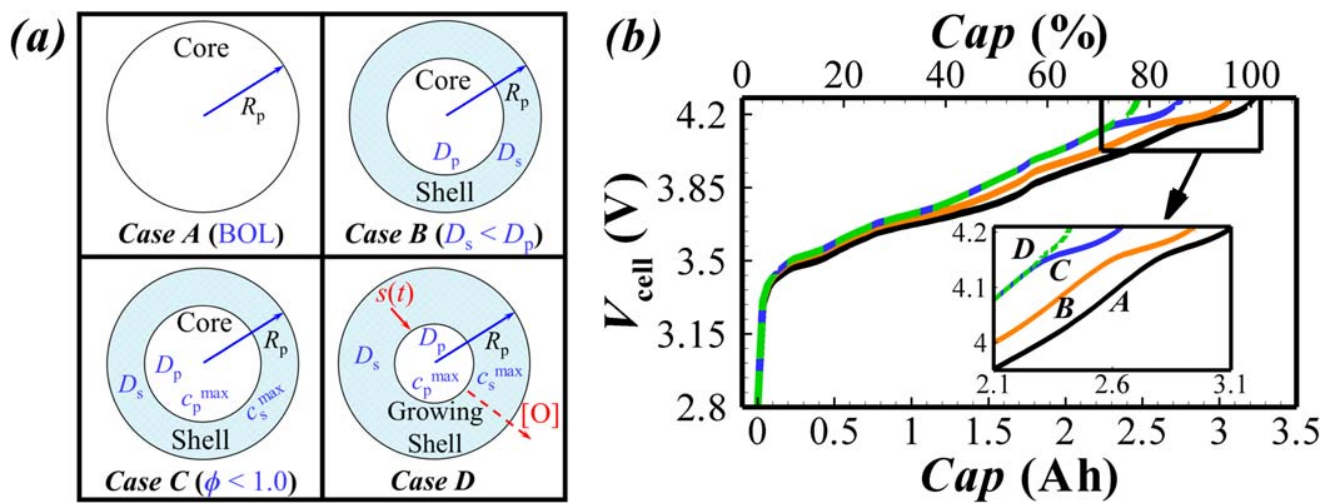

Figure 4. Voltage vs capacity curves predicted by mSPM during the charging of a Li-ion cell with four possible hypothetical configurations of PE. Plot (a) schematically shows the possible configurations. Case A corresponds to the beginning of life (BOL), when PE consists of a core, characterised by Li-ion diffusivity $D_{\mathrm{p}}$. Case B corresponds to PE consisting of core and shell, the latter characterised by Li-ion diffusivity $D_{\mathrm{s}}$, with, $D_{\mathrm{s}}<D_{\mathrm{p}}$. In this case, it is assumed that the maximum concentration of Li-ions in the core and shell is the same $(\phi=1)$. Case $\mathrm{C}$ corresponds to PE for which $c_{\mathrm{s}}^{\max }<c_{\mathrm{p}}^{\max }(\phi<1)$. Case $\mathrm{D}$ is case $\mathrm{C}$ plus the addition of shell growth and [O]-evolution. Plot (b) shows the evolution of cell voltage $\left(V_{\text {cell }}\right)$ with the charging capacity (Cap) of the cell corresponding to cases A-D. The parameters used for these simulations are, $s_{\mathrm{i}}=0.87$ (for cases B-D), $T_{\mathrm{amb}}=298 \mathrm{~K}, I_{\mathrm{app}}=\mathrm{C} / 2$, and $c^{*}=0.3$. The other parameters required for these simulations are listed in Tables I and II.

a finite thickness of $s_{\mathrm{i}}$ (as shown in case B) changes the diffusion dynamics of the Li-ions in the PE as discussed in Fig. 2. Slower diffusivity of the Li-ions $\left(D_{\mathrm{s}}\right)$ through the shell reduces the surface concentration $\left(c_{\mathrm{s}}^{\text {surf }}\right)$ as shown by the concentration profiles in Fig. 2b. The open-circuit potential (OCP) profiles shown in Figs. S1a and S1b show that the OCP for the PE $\left(U_{\mathrm{p}}\right)$ gradually increases with the reduction in $x_{\mathrm{p}}^{\text {surf }}$. The faster reduction in $x_{\mathrm{p}}^{\text {surf }}$ for case B compared to case A causes a reduction in the useable or accessible capacity when the upper cell voltage limit is fixed at $4.2 \mathrm{~V}$ as shown by the curve B in Fig. 4b (see inset). This effect would manifest as capacity and power fade. Although, in this article, we have only illustrated capacity fade for constant current charging. A pulse/step charging-discharging current can be used as input to obtain the corresponding variation in cell voltage with time (voltage profile). These current-voltage results can be used to quantify the power fade as one would do in an experimental setting.

The material properties of the core and shell are different, so their maximum intercalatable Li-ion capacity is different too. Case $\mathrm{C}$ represents a PE consisting of a shell with a lower maximum Li-ion capacity compared to the core. This, therefore, reduces the actual baseline capacity of the PE, essentially it is a type of loss of active material (LAM), accompanied by a loss of lithium inventory (LLI). Therefore, for this model to reproduce actual capacity fade, the capacity of the shell must be lower than the core. In case $\mathrm{D}$, the passivation layer formation and [O]-evolution reaction is turned on, and begins to change the behaviour of the cell as soon as the Li-ion concentration reduces below $c^{*}$. The increase in the shell thickness, 
Effect of $D_{0}$

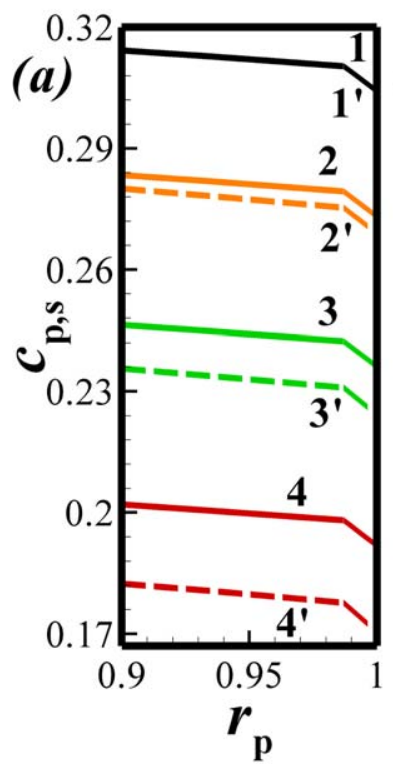

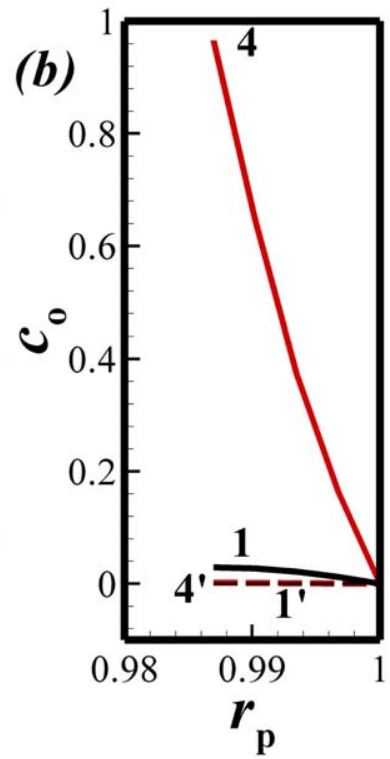

$$
\begin{aligned}
& D_{0}=1.0 \times 10^{-6} \text { (Solid lines) } \\
& D_{0}=1.0 \times 10^{-1} \text { (Broken lines) }
\end{aligned}
$$

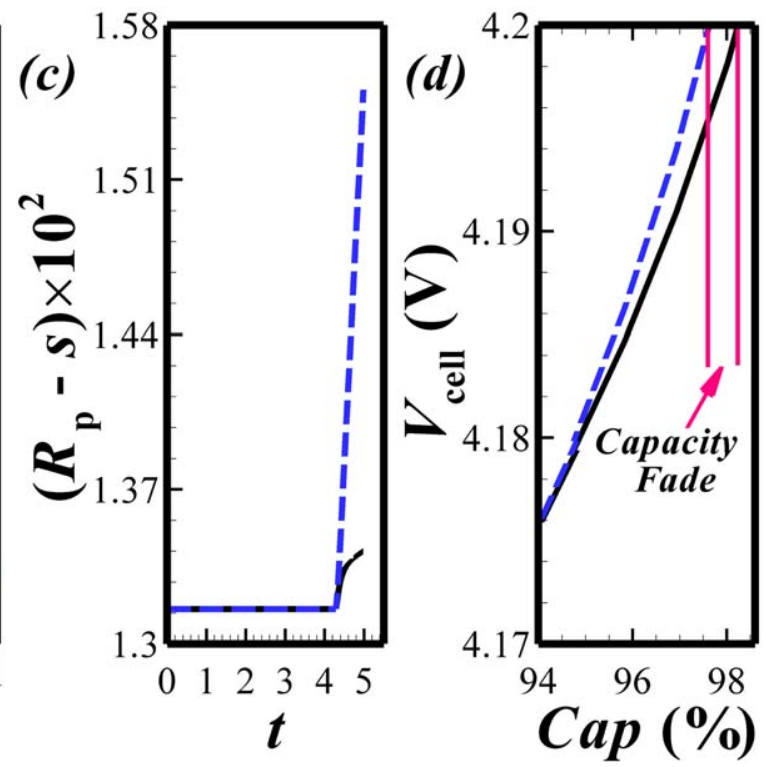

Figure 5. mSPM results showing the influence of [O]-diffusion on the capacity fade of a Li-ion cell, for $D_{\mathrm{o}}=1.0 \times 10^{-6}$ (sloid lines) and $D_{\mathrm{o}}=1.0 \times 10^{-1}$ (broken lines). Plots (a) and (b) show the variation of $\mathrm{Li}$-ion concentration $\left(c_{\mathrm{p}, \mathrm{s}}\right)$ and [O]-concentration $\left(c_{\mathrm{o}}\right)$ across PE particle radius $\left(r_{\mathrm{p}}\right)$. Lines $1-4$ [1" $\left.-4^{\prime \prime}\right]$ correspond to the concentration profiles at times, $t=4.24,4.44,4.69$, and 4.99 for $D_{\mathrm{o}}=1.0 \times 10^{-6}\left[D_{\mathrm{o}}=1.0 \times 10^{-1}\right]$. Plot (c) shows the time evolution of shell thickness $\left(R_{\mathrm{p}}-s\right)$. Plot $(\mathrm{d})$ shows the variation in cell voltage $\left(V_{\text {cell }}\right)$ with capacity $(C a p)$. The parameter values used in the simulations are, $s_{\mathrm{i}}=0.99, T_{\mathrm{amb}}=$ $298 \mathrm{~K}, I_{\text {app }}=\mathrm{C} / 2, c^{*}=0.3$, and $K_{1}=0.01$. The other essential parameters used for these simulations are listed in Tables I and II.

$x_{\mathrm{p}}^{\text {surf }}$ reduces the capacity further with the combined effect of LAM, LLI, and increased effective cell resistance, as shown in Fig. 4b (see inset). Notably, in practice, cases B-D will happen together. Experimentally, an individual can only obtain curves A at BOL and $\mathrm{D}$ after cycling the cell many times or storage at high voltages for a long time. Figure 4 summarizes that the initial presence and formation of the shell during charging as well as [O]-evolution instigate LAM, LLI, and resistance to engender the capacity fade of the Li-ion cell.

[O]-diffusion vs reaction kinetics.-The diffusion of [O] and the reaction kinetics of both the passivation layer formation and the $[\mathrm{O}]$-evolution reaction are the main phenomena that control the rate of degradation of the PE. Figure 5 shows the effect of [O]-diffusivity $\left(D_{\mathrm{o}}\right)$ on the concentration profiles $\left(c_{\mathrm{p}}\right.$ and $\left.c_{\mathrm{o}}\right)$, shell growth $\left(R_{\mathrm{p}}-s\right)$, and cell capacity (Cap). An increase in $D_{\mathrm{o}}$ reduces the Li-ion concentration at the PE particle surface $\left(c_{\mathrm{s}}^{\text {surf }}\right)$, as shown by the broken lines $\left(1^{\prime}-4\right)$ with respect to the solid lines (1-4) in Fig. 5a. However, [O]-concentration $\left(c_{\mathrm{o}}\right)$ at core-shell interface $(s)$ is much higher (line 4) when [O]-diffusivity $\left(D_{\mathrm{o}}\right)$ is lower in the shell as shown in Fig. 5b. Higher $D_{\mathrm{o}}$ ensures $c_{\mathrm{o}}$ remains low at $s$ which drives the shell formation reaction in the forward direction. The forward reaction enhances shell formation which increases shell thickness $\left(R_{\mathrm{p}}-s\right)$ near the PE particle boundary as shown in Fig. $5 \mathrm{c}$. Figure $5 \mathrm{~d}$ verifies that a higher $[\mathrm{O}]$-diffusion coefficient $\left(D_{\mathrm{o}}\right)$ leads to higher capacity fade, as it enhances shell growth, as discussed in Fig. 4.

Figure 6 presents the influence of reaction kinetics on the Li-ion and [O]-concentration profiles $\left(c_{\mathrm{p}}\right.$ and $\left.c_{\mathrm{o}}\right)$, shell growth $\left(R_{\mathrm{p}}-s\right)$, and capacity (Cap) of the cell. Figure 6a shows a reduction in $c_{\mathrm{s}}^{\text {surf }}$ with the increase in the forward rate $\left(K_{1}\right)$ of the phase transition reaction. Increasing $K_{1}$ produces more [O] and enhances shell formation, thus increasing both $c_{\mathrm{o}}$ and $\left(R_{\mathrm{p}}-s\right)$, as shown in Figs. $6 \mathrm{~b}$ and $6 \mathrm{c}$, respectively. An increase in the shell thickness affects the capacity fade of the cell, as shown in Fig. 6d. The results obtained in Figs. 5 and 6 can be rationalised by noting that a higher [O]-diffusivity $\left(D_{\mathrm{o}}\right)$ allows the $[\mathrm{O}]$ produced at the core-shell interface to migrate away towards the particle surface more readily, thereby lowering the [O]concentration $\left(c_{\mathrm{o}}\right)$ at the interface $(s)$. The backwards reaction is thus stifled, which results in an increased net reaction rate $\left(K_{1}-K_{2} c_{\mathrm{o}}\right)$. Whenever the forward reaction is favoured, the shell formation itself is favoured, causing higher capacity fade.

Figures 5 and 6 present the influence of varying the magnitude of $D_{\mathrm{o}}$ and $K_{1}$ individually, while keeping the other parameter constant. The effect of both $D_{\mathrm{o}}$ and $K_{1}$ is presented in Fig. 7. Figures $7 \mathrm{a}$ and $7 \mathrm{~b}$ show the contours of cell capacity in $D_{\mathrm{o}}-K_{1}$ plane for initial shell thickness, $R_{\mathrm{p}}-s_{\mathrm{i}}=0.01$ and 0.08 , respectively. For smaller shell thickness, [O]-diffuses out very fast and $K_{1}$ dominates the capacity fade as can be observed following the constant capacity lines across $K_{1}$ (higher capacity fade due to a relatively smaller change in the values of $K_{1}$ ) in Fig. 7a which is the reason the amount of capacity fade obtained is high. However, for larger shell thickness, [O]-diffusion becomes the limiting factor, and the amount of capacity fade is low as shown in Fig. 7b. The higher variation in the constant capacity lines is obtained only in the lower $D_{\mathrm{o}}$ value regions. A larger shell thickness corresponds to higher degradation via LAM and LLI. If the reaction rate $\left(K_{1}\right)$ and [O]-diffusion $\left(D_{\mathrm{o}}\right)$ are both high, a higher rate of LAM and LLI is to be expected, as evident from the results obtained in Figs. $7 \mathrm{a}$ and $7 \mathrm{~b}$.

Figures 5-7 summarize the influence of [O]-diffusion and the reaction kinetics on the capacity fade of a Li-ion cell during the structural changes of NMC811 materials. The net rate, $\left(K_{1}-K_{2} c_{\mathrm{o}}\right)$, which governs the structural change reaction of the PE, reveals that if [O]-diffusion is slow relative to the forward reaction rate, then the capacity fade is "diffusion dominated," but if [O]-diffusion is fast relative to the forward reaction rate, then the capacity fade is "reaction rate dominated." As the shell thickens, corresponding to a more aged cell, the capacity fade becomes more "diffusion dominated."

Beside [O]-diffusion and reaction kinetics of the interfacial chemical reaction, the other parameters that may influence the 


\section{Effect of $K_{1}$}

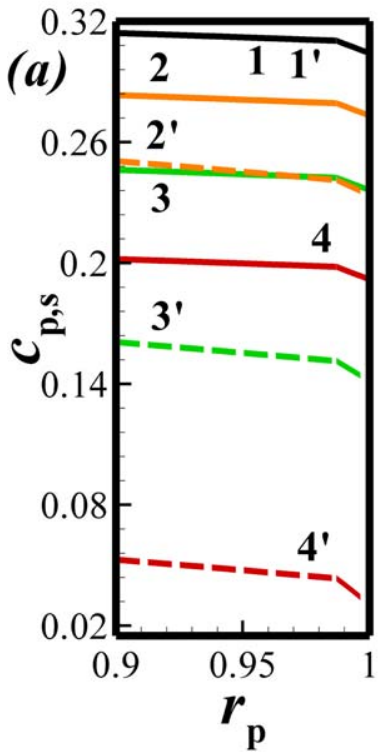

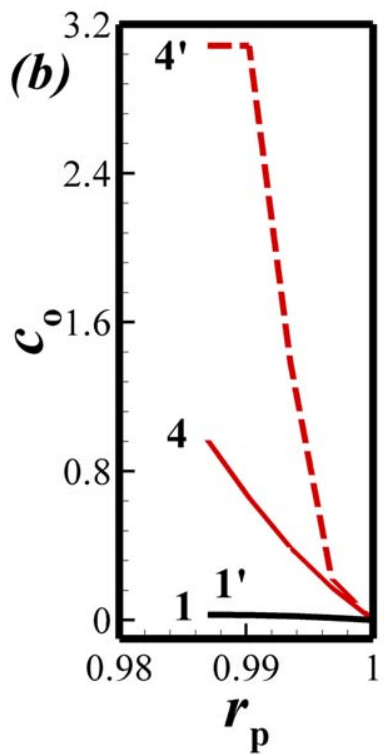

$$
\begin{aligned}
& K_{1}=0.01 \text { (Solid lines) } \\
& K_{1}=0.1 \text { (Broken lines) }
\end{aligned}
$$
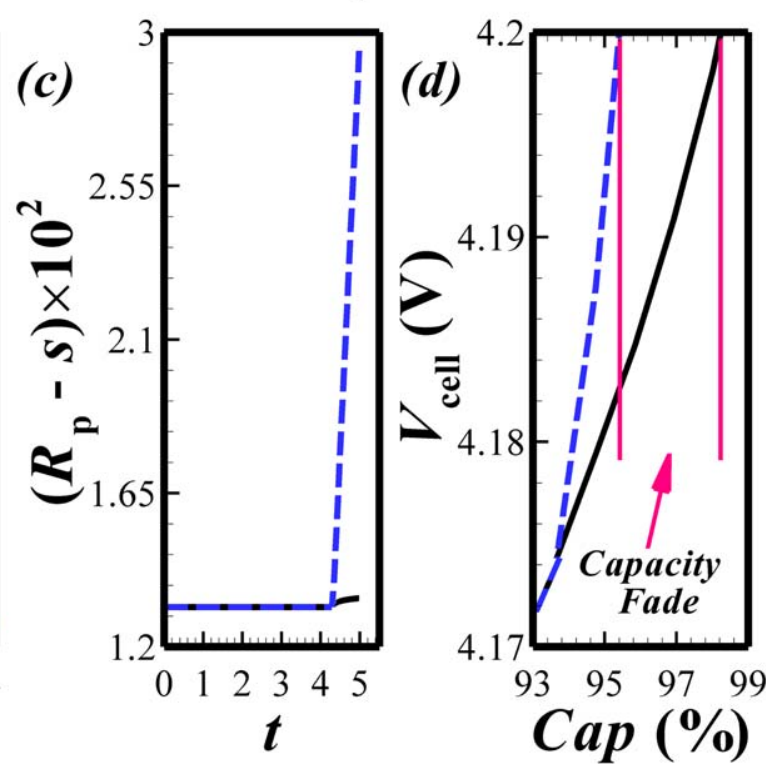

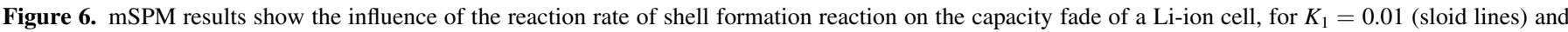

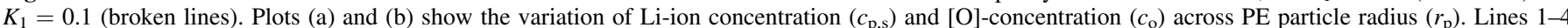

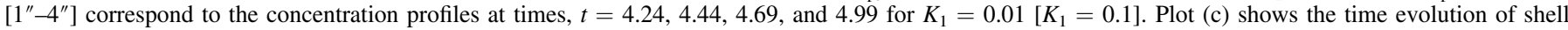

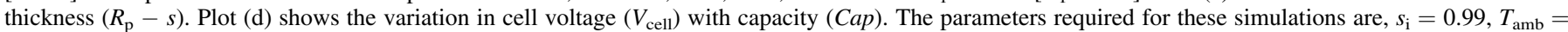

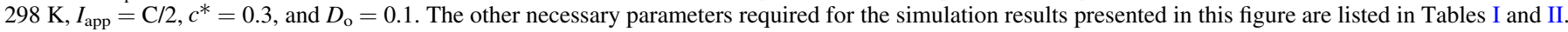
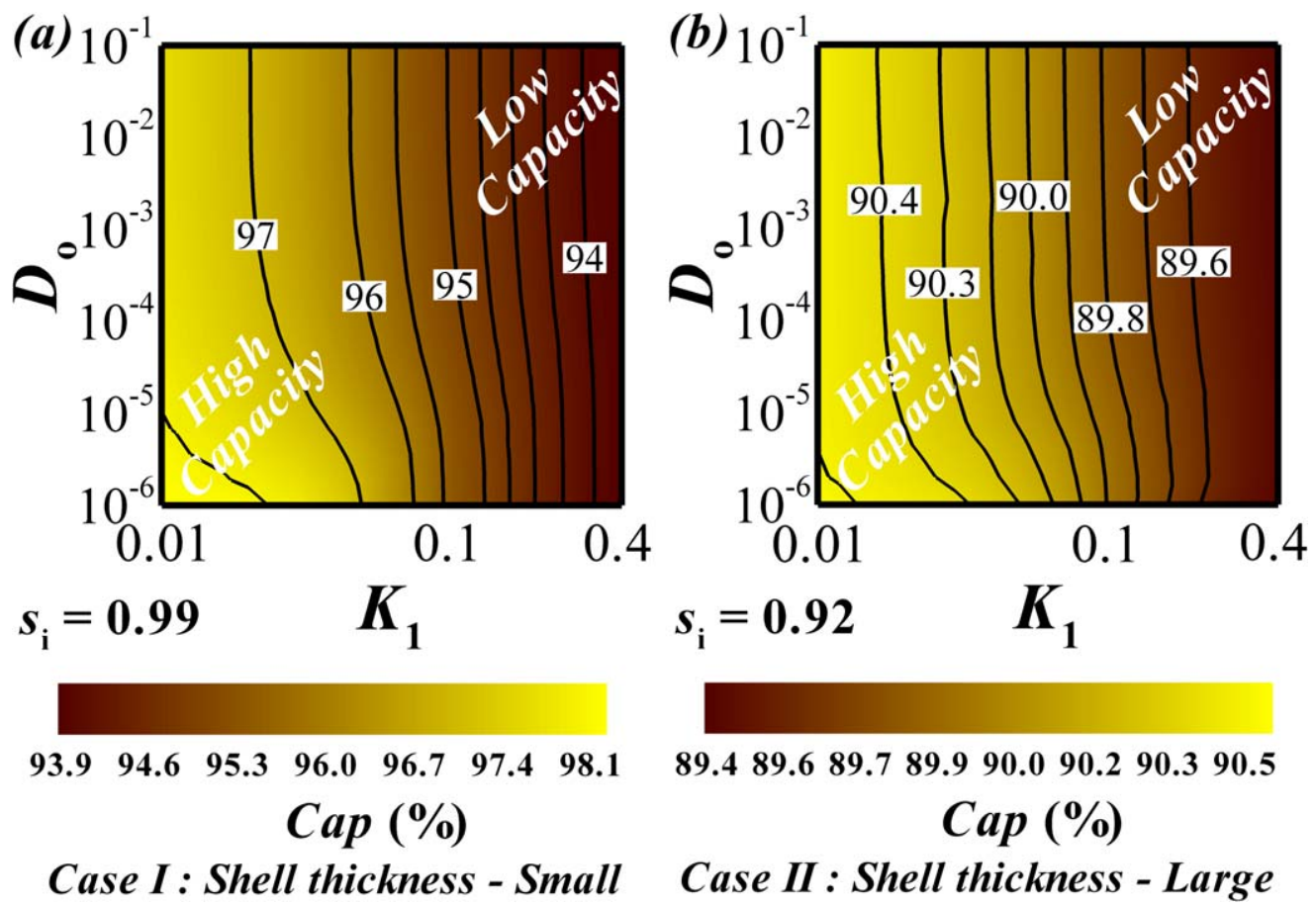

Figure 7. mSPM results to illustrate two degradation modes: "diffusion-dominated" and "reaction-dominated" capacity fade of a Li-ion cell. Plots (a) and (b) show the contours of ( $\mathrm{Cap}$ ) as a function of $D_{\mathrm{o}}$ and $K_{1}$ for an initial core-shell interface located at $s_{\mathrm{i}}=0.99$ (Case I) and $s_{\mathrm{i}}=0.92$ (Case II), respectively. Solid lines represent constant capacity lines. The parameters used for the simulations are, $T_{\mathrm{amb}}=298 \mathrm{~K}, I_{\mathrm{app}}=\mathrm{C} / 2$, and $c^{*}=0.3$. The other necessary parameters used for these simulations are listed in Tables I and II.

capacity of the cell are: the Li-ion-diffusivity through the shell $\left(D_{\mathrm{s}}\right)$, initial shell thickness $\left(R_{\mathrm{p}}-s_{\mathrm{i}}\right)$, and amount of Li-ions lost during shell formation $(\phi)$. As expected, a reduction in $D_{\mathrm{s}}$ and $\phi$ reduces the capacity of the cell, whereas a larger initial shell thickness $\left(R_{\mathrm{p}}-s_{\mathrm{i}}\right)$ reduces the capacity of the cell significantly. The theoretical formulation presented here captures these dependencies and the corresponding simulation results are presented in Fig. S4 of ESI. Notably, these three parameters are specific for a particular PE material, and their values are relatively easily obtainable from either fundamental material properties or molecular simulation studies. In 
contrast, the two interfacial phenomena, i.e. the reaction rate and the [O]-diffusion rate control the phase transition of NMC811 material during charging and lead to two markedly different degradation pathways, as presented in Fig. 7.

Perspective for a higher number of charging cycles.-Due to computation speed, the degradation parameters used to obtain the results presented in Figs. 2-7 are chosen to accelerate the degradation by increasing the shell thickness exaggeratedly within the first cycle. It is known that the growth of the passivation layer happens over potentially thousands of cycles. It was checked that lower values of the degradation parameters, such as $D_{\mathrm{o}}$ and $K_{1}$, reproduce similar results as those presented above over the first few cycles. The model predictions presented here aim to reveal the physics of this specific degradation mechanism, and the effects retrieved by the model. These remain valid for the accelerated degradation modelled. Quantitative comparisons with experimental data on degradation and the detailed analysis of the influence of charging-discharging cycles at various operating conditions and remain the subject of future work.

\section{Conclusions}

The influence of structural changes of a high nickel cathode material, typified by NMC811, on the degradation of a Li-ion cell have been explored through a comprehensive thermally-coupled, physics-informed continuum scale model, for the first time. The governing equations and boundary conditions of the conventional single-particle model (SPM) are modified to incorporate the decomposition of the bulk positive electrode material into a shell layer via the evolution of [O] and a shrinking-core model. [O]-generated at the bulk-passivation layer interface diffuses through the shell and process modelled as zero [O]-concentration at the particle surface. The effect of the diffusion rate of Li-ions and [O] through the shell and the rate of the shell formation reaction are both studied in this model. The model is shown to predict capacity fade due to the loss of active (bulk) material (LAM) and loss of lithium inventory (LLI), and power fade due to slower diffusion of lithium ions through the passivation layer.

A detailed analysis of the simulation results reveals that both [O]diffusion through the shell and the reaction kinetics of the shell formation reaction can control the rate of degradation. The model can therefore reproduce two limiting cases, "diffusion dominated" if $[\mathrm{O}]$-diffusion is slow and/or the shell is thick, and "reaction dominated" if [O]-diffusion is fast and/or if the passivation layer is thin. The transition between the two limiting cases is a result of a complex interplay between the relative rates. As the shell thickens, corresponding to a more degraded cell, the capacity fade becomes more "diffusion limited."

This is the first time that a continuum model of the degradation of high nickel positive electrode materials is developed. This is done on the basis of fundamental physics principles, together with the comprehensive review of materials characterisation literature for NMC positive electrodes. The model constitutes a significant and novel addition to the growing repertoire of degradation models for Li-ion batteries and a necessary step towards creating a unified model of degradation for Li-ion batteries.

\section{Acknowledgments}

The authors thank financial support received from EPSRC Faraday Institution Multiscale Modelling project (EP/S003053/1, grant number FIRG003).

\section{Appendix A. Derivation Steps}

A.1. Derivation steps of Eq. 7.-Oxygen in the core react at the core-shell interface to create [O] according to the following,

$$
\begin{aligned}
& \frac{d}{d t}\left(\iiint_{\text {core }} c_{\mathrm{oc}} d V\right)=-g \iint_{r=s} d A \Rightarrow c_{\mathrm{oc}} \frac{4 \pi}{3} \frac{d}{d t}\left(s^{3}\right) \\
& \quad=-g 4 \pi s^{2} \Rightarrow g=-c_{\mathrm{oc}} \dot{s} .
\end{aligned}
$$

The variable $g$ is the molecular flux of [O] at the core-shell interface. The total amount of Li-ions available for intercalation/ deintercalation in the PE can either diffuse out through the particle boundary or get consumed in the shell during the [O]-formation reaction,

$$
\frac{d}{d t} \iiint_{P E}\left(c_{\mathrm{p}}+\phi c_{\mathrm{s}}\right) d V=-\iint_{r=R_{\mathrm{p}}}\left(\mathbf{F}_{\mathrm{s}} \cdot \mathbf{n}\right) d A-g \iint_{r=s} d A .
$$

The notations, $\mathbf{n}, V$, and $A$ denote the outward normal vector, volume, and surface over which the integrations are being carried, respectively. The expression obtained in Eq. A.1 is replaced in Eq. A.2 to obtain,

$$
\frac{d}{d t} \iiint_{P E}\left(c_{\mathrm{p}}+\phi c_{\mathrm{s}}\right) d V=-\iint_{r=R_{\mathrm{p}}}\left(\mathbf{F}_{\mathrm{s}} \cdot \mathbf{n}\right) d A+\dot{s} c_{\mathrm{oc}} \iint_{r=s} d A .
$$

The total amount of Li-ions should be conserved. Thus, we can write,

$$
\iiint_{\text {core }}\left(c_{\mathrm{p}, t}+\nabla \cdot \mathbf{F}_{\mathrm{p}}\right) d V+\iiint_{\text {shell }}\left(\left(\phi c_{\mathrm{s}}\right)_{, t}+\nabla \cdot \mathbf{F}_{\mathrm{s}}\right) d V=0 .
$$

Using Reynolds transport theorem (RTT) and divergence theorem we obtain,

$$
\begin{aligned}
& \frac{d}{d t} \iiint_{P E}\left(c_{\mathrm{p}}+\phi c_{\mathrm{s}}\right) d V-\iint_{r=0, s}(\mathbf{v} \cdot \mathbf{n}) c_{\mathrm{p}} d A \\
& \quad+\iint_{r=0, s}\left(\mathbf{F}_{\mathrm{p}} \cdot \mathbf{n}\right) d A-\iint_{r=s, R_{p}}(\mathbf{v} \cdot \mathbf{n}) \phi c_{\mathrm{s}} d A \\
& \quad+\iint_{r=s, R_{p}}\left(\mathbf{F}_{\mathrm{s}} \cdot \mathbf{n}\right) d A=0
\end{aligned}
$$

where $\mathbf{v}$ is the velocity of the area element considered for individual surface integration. Equation A.3 is replaced in Eq. A.5 and then rearranged to obtain,

$$
\iint_{r=s}\left[\dot{s} c_{\mathrm{oc}}-\dot{s} c_{\mathrm{p}}+\dot{s} \phi c_{\mathrm{s}}+F_{\mathrm{p}}-F_{\mathrm{s}}\right] d A=0 .
$$

Considering Eq. 6 of the main manuscript we can write Eq. A.6 as,

$$
\left.\left(F_{\mathrm{s}}-F_{\mathrm{p}}\right)\right|_{r=s}+\left.\dot{s}(1-\phi) c_{\mathrm{p}}\right|_{r=s}-\dot{s} c_{\mathrm{oc}}=0,
$$

which is the exact similar form as presented in Eq. 7 of the main manuscript.

A.2. Derivation steps of Eq. 9.- The total amount of oxygen contained within PE particle and leaving the particle surface should be conserved. Thus,

$$
\iiint_{\text {core }}\left(c_{\mathrm{oc}, t}+\nabla \cdot \mathbf{F}_{\mathrm{oc}}\right) d V+\iiint_{\text {shell }}\left(c_{\mathrm{o}, t}+\nabla \cdot \mathbf{F}_{\mathrm{o}}\right) d V=0,
$$

where, $\mathbf{F}_{\mathrm{oc}}$ is the local mass flux of oxygen in the core. The total amount of $[\mathrm{O}]$ can only leave through the particle boundary which we can express as, 


$$
\frac{d}{d t} \iiint_{P E}\left(c_{\mathrm{oc}, t}+c_{\mathrm{o}, t}\right) d V=-\iint_{r=R_{\mathrm{p}}}\left(\mathbf{F}_{\mathrm{o}} \cdot \mathbf{n}\right) d A .
$$

Using Eqs. A.8 and A.9, RTT, divergence theorem, and following the similar procedure presented in Appendix A.1. we obtain the boundary condition for [O]-diffusion at the core-shell interface as,

$$
\left.F_{\mathrm{o}}\right|_{r=s}+\left.\dot{s}\left(c_{\mathrm{oc}}-c_{\mathrm{o}}\right)\right|_{r=s}=0 .
$$

A.3. Derivation steps of Eq. 13.-The rate of generation of [O] following the reaction kinetics of Eq. 12 can be written as,

$$
g=\left\{\begin{array}{lc}
k_{1}^{\prime} c_{\mathrm{mo}_{2}}-k_{2}^{\prime} c_{\mathrm{mo}} c_{\mathrm{o}} & c_{\mathrm{p}}<c^{*} \\
0 & c_{\mathrm{p}}>c^{*}
\end{array}\right\} .
$$

Using Eqs. A.1 and A.11 we can write,

$$
\dot{s}=-\left\{\begin{array}{lc}
k_{1}-k_{2} c_{\mathrm{o}} & c_{\mathrm{p}}<c^{*} \\
0 & c_{\mathrm{p}}>c^{*}
\end{array}\right\},
$$

where the redefined reaction rate constants are, $k_{1}=k_{1}^{\prime} c_{\mathrm{mo}_{2}} / c_{\mathrm{oc}}$ and $k_{2}=k_{2}^{\prime} c_{\mathrm{mo}} / c_{\mathrm{oc}}$.

\section{Appendix B. Non-Dimensional Equations}

The governing equations and boundary conditions are made nondimensional by setting, $\left(\hat{c}_{\mathrm{p}}, \hat{c}_{\mathrm{s}}, \hat{c}_{\mathrm{pi}}, \hat{c}_{\mathrm{o}}, \hat{c}_{\mathrm{oc}}\right)=\left(c_{\mathrm{p}}, c_{\mathrm{s}}, c_{\mathrm{pi}}, c_{\mathrm{o}}, c_{\mathrm{oc}}\right) /$ $c_{\mathrm{p}}^{\max },\left(\hat{c}_{\mathrm{n}}, \hat{c}_{\mathrm{ni}}\right)=\left(c_{\mathrm{n}}, c_{\mathrm{ni}}\right) / c_{\mathrm{n}}^{\max },\left(\hat{r}_{\mathrm{p}}, \hat{s}\right)=\left(r_{\mathrm{p}}, s\right) / R_{\mathrm{p}}, \hat{r}_{\mathrm{n}}=r_{\mathrm{n}} / R_{\mathrm{n}}$, $\left(\hat{D}_{\mathrm{p}}, \hat{D}_{\mathrm{s}}, \hat{D}_{\mathrm{o}}, \hat{D}_{\mathrm{n}}\right)=\left(D_{\mathrm{p}}, D_{\mathrm{s}}, D_{\mathrm{o}}, D_{\mathrm{n}}\right) / D_{\mathrm{p}}^{\text {ref }}, \quad \hat{J}_{\mathrm{p}}=J_{\mathrm{p}} R_{\mathrm{p}} / D_{\mathrm{p}}^{\text {ref }} c_{\mathrm{p}}^{\max }$, $\hat{J}_{\mathrm{n}}=J_{\mathrm{n}} R_{\mathrm{n}} / D_{\mathrm{p}}^{\text {ref }} c_{\mathrm{n}}^{\max }$, and $\hat{t}=t D_{\mathrm{p}}^{\text {ref }} / R_{\mathrm{p}}^{2}$. The local radius $(r)$ of the $\mathrm{PE}$ and NE is denoted as $r_{\mathrm{p}}$ and $r_{\mathrm{n}}$, respectively. We have redefined the dimensional chemical reaction rate constants in non-dimensional form as, $K_{1}=\left(R_{\mathrm{p}} / D_{\mathrm{p}}^{\text {ref }}\right) k_{1}$ and $K_{2}=\left(R_{\mathrm{p}} c_{\mathrm{p}}^{\max } / D_{\mathrm{p}}^{\text {ref }}\right) k_{2}$. Although the rescaled variables are represented by hats, however, the final form of the variables are shown without the hats, for brevity.

The resulting coupled governing equations [Eqs. 1-3], boundary [Eqs. 4-7 and 9-10] and initial [Eqs. 8 and 11] conditions, and core-shell interfacial dynamics equation [Eq. 13] for PE can be written as,

$$
\begin{gathered}
r_{\mathrm{p}}^{2} c_{\mathrm{p}, t}-D_{\mathrm{p}}\left(r_{\mathrm{p}}^{2} c_{\mathrm{p}, r_{\mathrm{p}}}\right)_{r_{\mathrm{p}}}=0, \\
r_{\mathrm{p}}^{2} \phi c_{\mathrm{s}, t}-D_{\mathrm{s}}\left(r_{\mathrm{p}}^{2} c_{\left.\mathrm{s}, r_{\mathrm{p}}\right), r_{\mathrm{p}}=0,}\right. \\
r_{\mathrm{p}}^{2} c_{\mathrm{o}, \mathrm{t}}-D_{\mathrm{o}}\left(r_{\mathrm{p}}^{2} c_{\mathrm{o}, r_{\mathrm{p}}}\right)_{r_{\mathrm{p}}}=0, \\
\left.c_{\mathrm{p}, r_{\mathrm{p}}}\right|_{r_{\mathrm{p}}=0}=0, \\
\left.c_{\mathrm{p}}\right|_{r_{\mathrm{p}}=s}-\left.\left.c_{\mathrm{s}}\right|_{r_{\mathrm{p}}=s}\right|_{r_{\mathrm{p}}=s}=0, \\
\left.D_{\mathrm{s}} c_{\mathrm{s}, r_{p}}\right|_{r_{\mathrm{p}}=s}+\dot{s}\left(\left.(1-\phi) c_{\mathrm{p}}\right|_{r_{\mathrm{p}}=s}-c_{\mathrm{oc}}\right)=0, \\
\left.D_{\mathrm{s}} c_{\mathrm{s}, r_{\mathrm{p}}}\right|_{r_{\mathrm{p}}=1}+J_{\mathrm{p}}=0, \\
\left.D_{\mathrm{o}} c_{\mathrm{o}, r_{\mathrm{p}}}\right|_{r_{\mathrm{p}}=s}-\left.\dot{s}\left(c_{\mathrm{oc}}-c_{\mathrm{o}}\right)\right|_{r_{p}=s}=0, \\
\left.c_{\mathrm{o}}\right|_{r_{\mathrm{p}}=1}=0, \\
\left.c_{\mathrm{p}}\right|_{t=0}=\left.c_{\mathrm{s}}\right|_{t=0}=c_{\mathrm{pi}},
\end{gathered}
$$

$$
\begin{gathered}
\left.c_{\mathrm{o}}\right|_{t=0}=0, \\
\dot{s}=-\left\{\begin{array}{lc}
K_{1}-K_{2} c_{\mathrm{o}} & c_{\mathrm{p}}<c^{*} \\
0 & c_{\mathrm{p}}>c^{*}
\end{array}\right\} .
\end{gathered}
$$

The non-dimensional governing equation [Eq. 14] and boundary [Eqs. 15-16] and initial [Eq. 17] conditions for NE are,

$$
\begin{gathered}
\left(R_{\mathrm{n}}^{2} / R_{\mathrm{p}}^{2}\right) r_{\mathrm{n}}^{2} c_{\mathrm{n}, t}-D_{\mathrm{n}}\left(r_{\mathrm{n}}^{2} c_{\mathrm{n}, r_{\mathrm{n}}}\right), r_{\mathrm{n}}=0, \\
\left.c_{\mathrm{n}, r_{\mathrm{n}}}\right|_{r_{\mathrm{n}}=0}=0, \\
\left.D_{\mathrm{n}} c_{\mathrm{n}, r_{\mathrm{n}}}\right|_{r_{\mathrm{n}}=1}+J_{\mathrm{n}}=0, \\
\left.c_{\mathrm{n}}\right|_{t=0}=c_{\mathrm{ni}} .
\end{gathered}
$$

The cell temperature is non-dimensionalised as $\left(T^{*}, T_{\mathrm{amb}}^{*}\right)=$ ( $\left.T, T_{\text {amb }}\right) / T_{\text {ref }}$. The dimensional energy balance [Eq. 23], the initial condition [Eq. 24], and temperature dependencies of parameters [Eqs. 25 and 27] are made dimensionless as following,

$$
\begin{array}{r}
\dot{T}^{*}=\frac{R_{\mathrm{p}}^{2}}{\rho \nu C_{\mathrm{p}} D_{\mathrm{p}}^{\text {ref }}}\left[I_{\mathrm{app}} T^{*}\left(U_{\mathrm{p}, T}\left(x_{\mathrm{p}}^{\text {surf }}\right)-U_{\mathrm{n}, T}\left(x_{\mathrm{n}}^{\text {surf }}\right)\right)\right. \\
\left.+\frac{I_{\mathrm{app}}}{T_{\text {ref }}}\left(V_{\text {cell }}-U_{\mathrm{p}}+U_{\mathrm{n}}\right)-h A_{\mathrm{c}}\left(T^{*}-T_{\mathrm{amb}}^{*}\right)\right], \\
\left.T^{*}\right|_{t=0}=T_{\mathrm{amb}}^{*}, \\
D_{\mathrm{i}}\left(T^{*}\right)=\exp \left[\frac{E a_{\mathrm{di}}}{R T_{\mathrm{ref}}}\left(1-\frac{1}{T^{*}}\right)\right],(\mathrm{i}=\mathrm{p}, \mathrm{s}, \mathrm{n}, \mathrm{o}) \\
K_{\mathrm{j}}\left(T^{*}\right) / K_{\mathrm{j}}^{\text {ref }}=\exp \left[\frac{E a_{\mathrm{kj}}}{R T_{\mathrm{ref}}}\left(1-\frac{1}{T^{*}}\right)\right] \cdot(\mathrm{j}=1,2)
\end{array}
$$

\section{Appendix C. Mapped Equations}

The transformed set of coupled equations [Eqs. B.1-B.12] is derived as,

$$
\begin{gathered}
c_{\mathrm{p}, t}-\frac{\eta \dot{s}}{s} c_{\mathrm{p}, \eta}-\frac{D_{p}}{\eta^{2} s^{2}}\left(\eta^{2} c_{\mathrm{p}, \eta}\right)_{, \eta}=0, \\
c_{\mathrm{s}, t}+\frac{\dot{s}(\chi-1)}{(1-s)} c_{\mathrm{s}, \chi}-\frac{D_{\mathrm{s}}}{\phi(1-s)^{2}(\chi(1-s)+s)^{2}} \\
\times\left((\chi(1-s)+s)^{2} c_{\mathrm{s}, \chi}\right)_{, \chi}=0, \\
c_{\mathrm{o}, t}+\frac{\dot{s}(\chi-1)}{(1-s)} c_{\mathrm{o}, \chi}-\frac{D_{\mathrm{o}}}{(1-s)^{2}(\chi(1-s)+s)^{2}} \\
\times\left((\chi(1-s)+s)^{2} c_{\mathrm{o}, \chi}\right)_{, \chi}=0, \\
\left.c_{\mathrm{p}, \eta}\right|_{\eta=0}=0, \\
\left.c_{\mathrm{p}}\right|_{\eta=1}-\left.c_{\mathrm{s}}\right|_{\chi=0}=0, \\
\left.D_{\mathrm{p}}(1-s) c_{\mathrm{p}, \eta}\right|_{\eta=1}-\left.D_{\mathrm{s}} s c_{\mathrm{s}, \chi}\right|_{\chi=0} \\
+\dot{s} s(1-s)\left(\left.(1-\phi) c_{\mathrm{p}}\right|_{\eta=1}-c_{\mathrm{oc}}\right)=0,
\end{gathered}
$$




$$
\begin{gathered}
\left.D_{\mathrm{s}} c_{\mathrm{s}, \chi}\right|_{\chi=1}+(1-s) J_{\mathrm{p}}=0, \\
\left.D_{\mathrm{o}} c_{\mathrm{o}, \chi}\right|_{\chi=0}-\left.(1-s) \dot{s}\left(c_{\mathrm{oc}}-c_{\mathrm{o}}\right)\right|_{\chi=0}=0, \\
\left.c_{\mathrm{o}}\right|_{\chi=1}=0, \\
\left.c_{\mathrm{p}}\right|_{t=0}=\left.c_{\mathrm{s}}\right|_{t=0}=c_{\mathrm{pi}}, \\
\left.c_{\mathrm{o}}\right|_{t=0}=0, \\
\dot{s}=-\left\{\begin{array}{ll}
K_{1}-K_{2} c_{\mathrm{o}} & c_{\mathrm{p}}<c^{*} \\
0 & c_{\mathrm{p}}>c^{*}
\end{array}\right\} .
\end{gathered}
$$

\section{ORCID}

Abir Ghosh (D) https://orcid.org/0000-0001-7345-1804

Monica Marinescu (D) https://orcid.org/0000-0003-1641-3371

\section{References}

1. O. Gröger, H. A. Gasteiger, and J.-P. Suchsland, "Review-electromobility: batteries or fuel cells?" J. Electrochem. Soc., 162, A2605 (2015).

2. R. Du, X. Hu, S. Xie, L. Hu, Z. Zhang, and X. Lin, "Battery aging- and temperature-aware predictive energy management for hybrid electric vehicles." J. Power Sources, 473, 228568 (2020)

3. J. Jaguemont, L. Boulon, and Y. Dubé, "A comprehensive review of lithium-ion batteries used in hybrid and electric vehicles at cold temperatures." Appl. Energy, 164, 99 (2016)

4. D. Andre, S.-J. Kim, P. Lamp, S. F. Lux, F. Maglia, O. Paschos, and B. Stiaszny, "Future generations of cathode materials: an automotive industry perspective." J. Mater. Chem. A, 3, 6709 (2015).

5. A. Kraytsberg and Y. Ein-Eli, "Higher, stronger, better... a review of 5 volt cathode materials for advanced lithium-ion batteries." Adv. Energy Mater., 2, 922 (2012).

6. P. Rozier and J. M. Tarascon, "Review-Li-rich layered oxide cathodes for nextgeneration Li-ion batteries: chances and challenges." J. Electrochem. Soc., 162 A2490 (2015).

7. I. Belharouak, Y. K. Sun, J. Liu, and K. Amine, "Li(Ni1/3Co1/3Mn1/3)O2 as a suitable cathode for high power applications." J. Power Sources, 123, 247 (2003).

8. J. Choi and A. Manthiram, "Role of chemical and structural stabilities on the electrochemical properties of layered $\mathrm{LiNi1} / 3 \mathrm{Mn} 1 / 3 \mathrm{Co} 1 / 3 \mathrm{O} 2$ cathodes." J. Electrochem. Soc., 152, A1714 (2005).

9. L. Song, J. Du, Z. Xiao, P. Jiang, Z. Cao, and H. Zhu, "Research progress on the surface of high-nickel nickel-cobalt-manganese ternary cathode materials: a mini review." Front. Chem., 8 (2020).

10. M. S. Whittingham, "Lithium batteries and cathode materials." Chem. Rev., 104, $4271(2004)$

11. S.-K. Jung, H. Gwon, J. Hong, K.-Y. Park, D.-H. Seo, H. Kim, J. Hyun, W. Yang, and K. Kang, "Understanding the degradation mechanisms of $\mathrm{LiNi}_{0.5} \mathrm{Co}_{0.2} \mathrm{Mn}_{0.3} \mathrm{O}_{2}$ cathode material in lithium ion batteries." Adv. Energy Mater., 4, 1300787 (2014).

12. H.-J. Noh, S. Youn, C. S. Yoon, and Y.-K. Sun, "Comparison of the structural and electrochemical properties of layered $\mathrm{Li}[\mathrm{NixCoyMnz}] \mathrm{O} 2(\mathrm{x}=1 / 3,0.5,0.6,0.7,0.8$ and 0.85 ) cathode material for lithium-ion batteries." J. Power Sources, 233, 121 (2013).

13. H. Gabrisch, T. Yi, and R. Yazami, "Transmission electron microscope studies of $\mathrm{LiNi} 1 / 3 \mathrm{Mn} 1 / 3 \mathrm{Co} 1 / 3 \mathrm{O} 2$ before and after long-term aging at $70{ }^{\circ} \mathrm{C} . "$ Electrochem Solid-State Lett., 11, A119 (2008).

14. W. Liu, P. Oh, X. Liu, M.-J. Lee, W. Cho, S. Chae, Y. Kim, and J. Cho, "Nickelrich layered lithium transition-metal oxide for high-energy lithium-ion batteries." Angew. Chem. Int. Ed., 54, 4440 (2015).

15. H. Konishi, T. Yuasa, and M. Yoshikawa, "Thermal stability of Li1-yNixMn(1 $-\mathrm{x}) / 2 \mathrm{Co}(1-\mathrm{x}) / 2 \mathrm{O} 2$ layer-structured cathode materials used in Li-ion batteries." J. Power Sources, 196, 6884 (2011).

16. H. Arai, S. Okada, Y. Sakurai, and J.-I. Yamaki, "Thermal behavior of $\mathrm{Li1}-\mathrm{yNiO}_{2}$ and the decomposition mechanism." Solid State Ionics, 109, 295 (1998).

17. I. Belharouak, D. Vissers, and K. Amine, "Thermal stability of the $\mathrm{Li}$ (Ni0.8Co0.15Al0.05)O2 cathode in the presence of cell components." J. Electrochem. Soc., 153, A2030 (2006)

18. S.-M. Bak, K.-W. Nam, W. Chang, X. Yu, E. Hu, S. Hwang, E. A. Stach, K.-B. Kim, K. Y. Chung, and X.-Q. Yang, "Correlating structural changes and gas evolution during the thermal decomposition of charged $\mathrm{LixNi}_{0.8} \mathrm{Co}_{0.15} \mathrm{Al}_{0.05} \mathrm{O}_{2}$ cathode materials." Chem. Mater., 25, 337 (2013).

19. S.-M. Bak, E. Hu, Y. Zhou, X. Yu, S. D. Senanayake, S.-J. Cho, K.-B. Kim, K Y. Chung, X.-Q. Yang, and K.-W. Nam, "Structural changes and thermal stability of charged LiNixMnyCozO $\mathrm{O}_{2}$ cathode materials studied by combined in situ timeresolved XRD and mass spectroscopy." ACS Appl. Mater. Interfaces, 6, 22594 (2014)
20. I. Belharouak, W. Lu, D. Vissers, and K. Amine, "Safety characteristics of $\mathrm{Li}\left(\mathrm{Ni}_{0.8} \mathrm{Co}_{0.15} \mathrm{Al}_{0.05}\right) \mathrm{O}_{2}$ and $\mathrm{Li}(\mathrm{Ni1} / 3 \mathrm{Co} 1 / 3 \mathrm{Mn} 1 / 3) \mathrm{O} 2 . "$ Electrochem. Commun., 8 , 329 (2006).

21. S.-T. Myung, K.-S. Lee, C. S. Yoon, Y.-K. Sun, K. Amine, and H. Yashiro, "Effect of AlF3 coating on thermal behavior of chemically delithiated Li0.35[Ni1/3Co1/ 3Mn1/3]O2." J. Phys. Chem. C, 114, 4710 (2010).

22. R. Jung, M. Metzger, F. Maglia, C. Stinner, and H. A. Gasteiger, "Oxygen release and its effect on the cycling stability of LiNixMnyCozO2 (NMC) cathode materials for Li-ion batteries." J. Electrochem. Soc., 164, A1361 (2017).

23. S. Saha, K. Kishor, S. Sivakumar, and R. G. S. Pala, "Models and mechanisms of oxygen evolution reaction on electrocatalytic surface." J. Indian Inst. Sci., 96, 325 (2016).

24. R. Jung, M. Metzger, F. Maglia, C. Stinner, and H. A. Gasteiger, "Chemical versus electrochemical electrolyte oxidation on NMC111, NMC622, NMC811, LNMO, and conductive carbon." J. Phys. Chem. Lett., 8, 4820 (2017).

25. R. Jung, P. Strobl, F. Maglia, C. Stinner, and H. A. Gasteiger, "Temperature dependence of oxygen release from $\mathrm{LiNi0} .6 \mathrm{Mn} 0.2 \mathrm{Co} 0.2 \mathrm{O} 2$ (NMC622) cathode materials for Li-ion batteries." J. Electrochem. Soc., 165, A2869 (2018).

26. F. Lin, I. M. Markus, D. Nordlund, T. C. Weng, M. D. Asta, H. L. L. Xin, and M. M. Doeff, "Surface reconstruction and chemical evolution of stoichiometric layered cathode materials for lithium-ion batteries." Nat. Commun., 5, 3529 (2014)

27. S. Muto, Y. Sasano, K. Tatsumi, T. Sasaki, K. Horibuchi, Y. Takeuchi, and Y. Ukyo, "Capacity-fading mechanisms of $\mathrm{LiNiO}_{2}$-based lithium-ion batteries." J. Electrochem. Soc., 156, A371 (2009).

28. D. P. Abraham, R. D. Twesten, M. Balasubramanian, I. Petrov, J. McBreen, and $\mathrm{K}$. Amine, "Surface changes on $\mathrm{LiNi}_{0.8} \mathrm{Co}_{0.2} \mathrm{O}_{2}$ particles during testing of highpower lithium-ion cells." Electrochem. Commun., 4, 620 (2002).

29. D. P. Abraham, R. D. Twesten, M. Balasubramanian, J. Kropf, D. Fischer J. McBreen, I. Petrov, and K. Amine, "Microscopy and spectroscopy of lithium nickel oxide-based particles used in high power lithium-ion cells." J. Electrochem. Soc., 150, A1450 (2003).

30. S. Hwang, W. Chang, S. M. Kim, D. Su, D. H. Kim, J. Y. Lee, K. Y. Chung, and E. A. Stach, "Investigation of changes in the surface structure of $\mathrm{LixNi}_{0.8} \mathrm{Co}_{0.15} \mathrm{Al}_{0.05} \mathrm{O}_{2}$ cathode materials induced by the initial charge." Chem. Mater., 26, 1084 (2014).

31. J. de Hoog, J. Jaguemont, A. Nikolian, J. Van Mierlo, P. Van Den Bossche, and N. Omar, "A combined thermo-electric resistance degradation model for nickel manganese cobalt oxide based lithium-ion cells." Appl. Therm. Eng., 135, 54 (2018).

32. T. Goh, M. Park, M. Seo, J. G. Kim, and S. W. Kim, "Capacity estimation algorithm with a second-order differential voltage curve for Li-ion batteries with NMC cathodes." Energy, 135, 257 (2017).

33. M. D. Radin, S. Hy, M. Sina, C. C. Fang, H. D. Liu, J. Vinckeviciute, M. H. Zhang, M. S. Whittingham, Y. S. Meng, and A. Van der Ven, "Narrowing the gap between theoretical and practical capacities in Li-ion layered oxide cathode materials." Adv. Energy Mater., 7, 1602888 (2017).

34. J. Vetter, P. Novák, M. R. Wagner, C. Veit, K. C. Möller, J. O. Besenhard, M. Winter, M. Wohlfahrt-Mehrens, C. Vogler, and A. Hammouche, "Ageing mechanisms in lithium-ion batteries." J. Power Sources, 147, 269 (2005).

35. D. Li, H. Li, D. Danilov, L. Gao, J. Zhou, R.-A. Eichel, Y. Yang, and P. H L. Notten, "Temperature-dependent cycling performance and ageing mechanisms of C6/LiNi1/3Mn1/3Co1/3O2 batteries." J. Power Sources, 396, 444 (2018).

36. E. Billy, M. Joulié, R. Laucournet, A. Boulineau, E. De Vito, and D. Meyer "Dissolution mechanisms of $\mathrm{LiNi} 1 / 3 \mathrm{Mn} 1 / 3 \mathrm{Co} 1 / 3 \mathrm{O} 2$ positive electrode material from lithium-ion batteries in acid solution." ACS Appl. Mater. Interfaces, 10, 16424 (2018).

37. R. Jung, R. Morasch, P. Karayaylali, K. Phillips, F. Maglia, C. Stinner, Y. ShaoHorn, and H. A. Gasteiger, "Effect of ambient storage on the degradation of Ni-rich positive electrode materials (NMC811) for Li-ion batteries." J. Electrochem. Soc., 165, A132 (2018)

38. E. M. Erickson, F. Schipper, T. R. Penki, J.-Y. Shin, C. Erk, F.-F. Chesneau, B. Markovsky, and D. Aurbach, "Review—recent advances and remaining challenges for lithium ion battery cathodes." J. Electrochem. Soc., 164, A6341 (2017).

39. P. Ramadass, B. Haran, P. M. Gomadam, R. White, and B. N. Popov, "Development of first principles capacity fade model for Li-ion cells." J. Electrochem. Soc., 151, A196 (2004).

40. G. Ning, R. E. White, and B. N. Popov, "A generalized cycle life model of rechargeable Li-ion batteries." Electrochim. Acta, 51, 2012 (2006).

41. M. Safari, M. Morcrette, A. Teyssot, and C. Delacourt, "Multimodal physics-based aging model for life prediction of Li-ion batteries." J. Electrochem. Soc., 156, A145 (2009).

42. H. Ekstrom and G. Lindbergh, "A model for predicting capacity fade due to SEI formation in a commercial graphite/LiFePO4 cell." J. Electrochem. Soc., 162, A1003 (2015).

43. X.-G. Yang, S. Ge, T. Liu, Y. Leng, and C.-Y. Wang, "A look into the voltage plateau signal for detection and quantification of lithium plating in lithium-ion cells.” J. Power Sources, 395, 251 (2018).

44. S. E. J. O'Kane, I. D. Campbell, M. W. J. Marzook, G. J. Offer, and M. Marinescu, "Physical origin of the differential voltage minimum associated with lithium plating in Li-ion batteries." J. Electrochem. Soc., 167, 090540 (2020).

45. C. Delacourt and M. Safari, "Life simulation of a graphite/LiFePO4 cell under cycling and storage." J. Electrochem. Soc., 159, A1283 (2012).

46. R. Narayanrao, M. M. Joglekar, and S. Inguva, "A phenomenological degradation model for cyclic aging of lithium ion cell materials." J. Electrochem. Soc., 160, A125 (2012).

47. R. Deshpande, M. Verbrugge, Y.-T. Cheng, J. Wang, and P. Liu, "Battery cycle life prediction with coupled chemical degradation and fatigue mechanics." J. Electrochem. Soc., 159, A1730 (2012). 
48. X. K. Lin, J. Park, L. Liu, Y. Lee, A. M. Sastry, and W. Lu, "A comprehensive capacity fade model and analysis for Li-ion batteries." J. Electrochem. Soc., 160, A1701 (2013).

49. J. M. Reniers, G. Mulder, and D. A. Howey, "Review and performance comparison of mechanical-chemical degradation models for lithium-ion batteries." J. Electrochem. Soc., 166, A3189 (2019).

50. A. Jana, G. M. Shaver, and R. E. Garcia, "Physical, on the fly, capacity degradation prediction of LiNiMnCoO2-graphite cells." J. Power Sources, 422, 185 (2019).

51. Q. Zhang and R. E. White, "Moving boundary model for the discharge of a $\mathrm{LiCoO} 2$ electrode." J. Electrochem. Soc., 154, A587 (2007).

52. G. K. Singh, G. Ceder, and M. Z. Bazant, "Intercalation dynamics in rechargeable battery materials: general theory and phase-transformation waves in $\mathrm{LiFePO}_{4}$." Electrochim. Acta, 53, 7599 (2008).

53. S. Santhanagopalan, Q. Z. Guo, P. Ramadass, and R. E. White, "Review of models for predicting the cycling performance of lithium ion batteries." J. Power Sources, 156, 620 (2006).

54. G. Ning and B. N. Popov, "Cycle life modeling of lithium-ion batteries." J. Electrochem. Soc., 151, A1584 (2004).

55. M. Guo, G. Sikha, and R. E. White, "Single-particle model for a lithium-ion cell thermal behavior." J. Electrochem. Soc., 158, A122 (2011).

56. T. F. Fuller, M. Doyle, and J. Newman, "Simulation and optimization of the dual lithium ion insertion cell.” J. Electrochem. Soc., 141, 1 (1994).
57. Battery Space, (2015), Product specification of the model INR18650 MJ1 3500mAh cell, Document No: LRB-PS-CY3450_MJ1, https://www.batteryspace. com/prod-specs/10388.pdf.

58. J. Sturm, A. Rheinfeld, I. Zilberman, F. B. Spingler, S. Kosch, F. Frie, and A. Jossen, "Modeling and simulation of inhomogeneities in a 18650 nickel-rich, silicon-graphite lithium-ion cell during fast charging." J. Power Sources, 412, 204 (2019).

59. G. Richardson, I. Korotkin, R. Ranom, M. Castle, and J. M. Foster, "Generalised single particle models for high-rate operation of graded lithiumion electrodes: systematic derivation and validation." Electrochim. Acta, 339 $135862(2020)$

60. S. G. Marquis, V. Sulzer, R. Timms, C. P. Please, and S. J. Chapman, "An asymptotic derivation of a single particle model with electrolyte." J. Electrochem. Soc., 166, A3693 (2019).

61. F. Schipper, E. M. Erickson, C. Erk, J.-Y. Shin, F. F. Chesneau, and D. Aurbach, "Review-recent advances and remaining challenges for lithium ion battery cathodes." J. Electrochem. Soc., 164, A6220 (2016).

62. I. W. M. Smith, "The temperature-dependence of elementary reaction rates: beyond Arrhenius." Chem. Soc. Rev., 37, 812 (2008).

63. G. Madabattula, B. Wu, M. Marinescu, and G. Offer, "How to design lithium ion capacitors: modelling, mass ratio of electrodes and pre-lithiation." J. Electrochem. Soc., 167, 013527 (2020). 